\title{
Dynamic Demand for New and Used Durable Goods without Physical Depreciation: The Case of Japanese Video Games*
}

\author{
Masakazu Ishihara ${ }^{\dagger}$ \\ Stern School of Business \\ New York University \\ Andrew Ching \\ Rotman School of Management \\ University of Toronto
}

First draft: May 8, 2010

This draft: Dec 15, 2012

\footnotetext{
${ }^{*}$ We have benefited from discussions with Sridhar Moorthy, Ron Borkovsky, Victor Aguirregabiria, Harikesh Nair, Avi Goldfarb, Susumu Imai, Nitin Mehta, Mengze Shi, Tanjim Hossain, David Soberman, Ig Horstmann, Andy Mitchell, Alon Eizenberg, Christos Genakos, Benjamin Shiller. We also thank seminar and conference participants at U of Toronto, Erasmus School of Economics, NYU, U of Michigan, U of Rochester, UT-Dallas, UBC, NUS, HKUST, Washington University-Saint Louis, OSU, UCLA, Columbia, Northwestern, UCSD, McMaster, UC Berkeley, Stanford, Chicago, 2009 Marketing Dynamics Conference, 2010/2012 IIOC, 2012 CKGSB Marketing Research Forum, and 2012 NBER Summer Institute Economics of IT and Digitization Workshop for their helpful comments. All remaining errors are ours.

${ }^{\dagger}$ Please direct all correspondence to Masakazu Ishihara, Stern School of Business, New York University. Email: mishihar@stern.nyu.edu.
} 


\title{
Dynamic Demand for New and Used Durable Goods without Physical Depreciation: The Case of Japanese Video Games
}

\begin{abstract}
For information/digital products, the used goods market has been viewed as a threat by producers. However, it is not clear if this view is justified because the used goods market also provides owners with an opportunity to sell their products. To investigate the impact of the used goods market on new goods sales, we collect a unique data set from the Japanese video game market. Based on the data, we develop and estimate a new dynamic structural model of consumers' buying and selling decisions. The estimation results show that the consumption value of owners depreciates much faster than that of potential buyers, and consumers are heterogeneous in transaction costs of buying and selling used copies. We also find evidence that new and used copies are not close substitutes, and consumers are forward-looking. The latter suggests that the future resale opportunity could increase consumers' willingness-to-pay for new copies. Using the estimates, we quantify the impact of eliminating the used game market on publishers' profits. We find that this policy would reduce the average profits per game by $10 \%$ if publishers do not adjust their prices. However, if they adjust prices optimally, it would increase the average profits per game by $19 \%$.
\end{abstract}

Keywords: Information/Digital Products, Durable Goods, Used Goods Market, Demand Estimation, Dynamic Programming, Transaction Costs, Satiation, Discount Factor, Bayesian Estimation. 


\section{Introduction}

The existence of used goods markets has been viewed as a serious problem by producers in information/digital product categories such as books, CDs/DVDs, and video games. They argue that the competition from used goods significantly lowers their profits and reduce the incentive to develop new products. For instance, book publishers and authors expressed their annoyance to Amazon over used books sold on its websites (Tedeschi 2004). Video game publishers in Japan attempted to kill off used video game retailing by suing used video game retailers (Hirayama 2006). Their main argument is that products like books and video games physically depreciate negligibly, but owners' consumption values can decline very quickly due to satiation. As a result, unlike products that physically depreciate more considerably (such as cars), producers of information/digital products may face competition from used goods that appear to be almost identical to new goods soon after the release of a new product.

However, their argument focuses only on one aspect of used goods markets (substitution effect), and ignores the possibility that transaction costs of buying and selling used goods could reduce the substitutability between new and used goods. Moreover, the existence of used goods markets provides consumers with a selling opportunity. If consumers are forward-looking and account for the future resale value when making a buying decision, the effective price consumers pay for a product will be lower than the price of the product (resale effect). This feature implies that the existence of used goods markets could increase the sales of new goods. Thus, whether the existence of used goods markets hurts or benefits new-good producers is an empirical question, and the answer depends on which effect, substitution or resale effect, dominates.

In light of these shortcomings, this paper contributes to the existing literature in two important dimensions. First, we assemble a new data set from the Japanese video game market, which includes weekly aggregate level data for 20 video game titles released in Japan between 2004 and 2008. The novel aspect of this data set is that, in addition to the sales and prices of new and used goods, which are the main variables focused in the previous works (e.g., Esteban and Shum 2007, Chen et al. 2011, Schiraldi 2011), it includes 
three new important variables which have not been studied before: (i) the resale value of used goods, ${ }^{1}$ (ii) the quantity of used goods retailers purchased from consumers, and (iii) the aggregate inventory level of used goods at retailers. They allow us to document new empirical regularities for the used video game market.

Second, based on this new data set, we develop and estimate a new structural model of consumers' buying and selling decisions of durable goods which do not suffer from physical depreciation. To our knowledge, this is the first dynamic model of forward-looking consumers that incorporates all of the following features: (i) new and used goods buying decisions, (ii) used goods selling decision, (iii) consumer expectations about future prices of new and used goods and resale values of used goods, (iv) transaction costs of buying and selling used goods, (v) the impact of used goods availability on buying decisions, and (vi) the depreciation of both owners' and potential buyers' consumption values. In our model, the expected discounted value of future payoffs from buying a product is determined by a dynamic consumer selling decision problem, which depends on the depreciation rate of owners' consumption values and future resale values. This modeling approach allows us to study the role of consumer expectation about future used-copy prices and resale values on current buying decisions. It should be highlighted that we allow owners' consumption values and potential buyers' consumption values to depreciate differently over time. In the previous empirical literature, these two depreciation rates are always assumed to be the same for owners and buyers (e.g., Esteban and Shum 2007, Chen et al. 2011, Schiraldi 2011). However, this assumption will likely be violated in information/digital product categories such as CDs/DVDs and video games because for product owners, the depreciation of consumption values is mainly due to satiation (satiation-based depreciation); but for potential buyers, it is mainly due to how long a product has been released (freshness-based depreciation). Our new data set, together with the structural model, allow us to measure these two concepts of depreciation separately.

To estimate the proposed dynamic model, we employ a new Bayesian Markov chain Monte Carlo (MCMC) algorithm first proposed by Imai, Jain and Ching (2009) (IJC algorithm), and is extended by

\footnotetext{
${ }^{1}$ We define resale value as the amount consumers receive when they sell their used video games to retailers. In Japan, retailers usually set a take-it-or-leave-it resale value for each game, and consumers sell their games at that resale value. Negotiation is uncommon.
} 
Ishihara and Ching (2012) to a non-stationary finite-horizon environment. As we will describe in the model section, our proposed framework uses a non-stationary finite-horizon dynamic programming model with stochastic continuous state variables. Ishihara and Ching (2012) argue that their algorithm has the potential to reduce the computational burden of this class of models. In this paper, we extend their algorithm further by combining it with the pseudo-policy function approach proposed by Ching (2010b), to address the potential price endogeneity problem. The method we propose augments unobserved aggregate shocks based on the joint-likelihood of the demand-side model and the pseudo-policy functions. Compared to the GMM approach used in the previous literature (Berry et al. 1995, Gowrisankaran and Rysman 2011), our approach does not require using the contraction mapping procedure to recover the mean utility level from observed market shares. Also, since we use the Bayesian data augmentation technique, unlike the simulated maximum likelihood method, we do not need to integrate out the unobserved shocks during the estimation. ${ }^{2}$

We apply this new empirical framework to the Japanese video game market, and study the impact of the used video game market on the profitability of video game publishers. The estimation results show that the consumption value of owners depreciates much faster than that of potential buyers. We also find evidence that consumers are forward-looking, suggesting that the future resale opportunity could increase consumers' willingness-to-pay for new copies. Consumers are heterogeneous in the transaction costs of buying and selling used copies - in particular, those who have relatively higher costs of buying also tend to have lower costs of selling. Moreover, we find that the transaction costs (both psychological costs and search costs) of buying a used copy reduce the substitutability between new and used copies in the Japanese video game market. Finally, we find that the demand for used copies is sensitive to its availability, and that the elasticity of used-copy supply declines over time. These findings might partly explain why the aggregate inventory of used-copy increases during the early stage of the product lifecycle.

Using the estimated model, we quantify the impact of eliminating the used video game market on newcopy sales and profits by conducting a counterfactual experiment. The video game market has recently tried to move towards using digital download as an alternative distribution channel. A complete switch to

\footnotetext{
${ }^{2}$ Yang et al. (2003) and Musalem et al. (2009) developed similar Bayesian algorithms for static models.
} 
digital download would essentially shut down the used video game market. Therefore, the results of this experiment could shed some light on this strategy. We first conduct the experiment by holding the prices of new copies at the observed level. On average, the elimination of the used video game market reduces consumers' willingness-to-pay for new copies of video games in the earlier part of the product lifecycle - this is mainly because the resale effect dominates the substitution effect. As a result, we find that the average profits per game declines by $10.3 \%$. We then compute the optimal prices of new copies when there is no used game market, and quantify the change in profits. We find that the optimal flat prices are on average $33 \%$ lower than the observed prices, and the elimination of the used video game market could increase the average profits per game by $18.6 \%$.

The rest of the paper is organized as follows. Section 2 reviews the previous literature. Section 3 describes the Japanese video game data used in this paper and presents some empirical regularities that have not been documented in the previous literature. Section 4 describes the dynamic discrete choice model of consumer buying and selling decisions. Section 5 explains the estimation strategy and identification. In Section 6, we discuss the parameter estimates and the counterfactual experiment results. Section 7 concludes.

\section{Literature Review}

Our research is closely related to previous studies on video game markets using the dynamic structural modeling approach (e.g., Nair 2007, Dubè et al. 2010, Liu 2010). ${ }^{3}$ In particular, Nair (2007) studies the intertemporal price discrimination for new games in the U.S. video game industry, and examines the role of consumer price expectation. However, none of these studies accounts for the potential impact of the used good market on the demand for new games. Previous empirical studies on new and used durable goods have largely focused on car (e.g., Esteban and Shum 2007, Chen et al. 2011, Schiraldi 2011, Engers et al. 2009, Purohit 1992) and housing markets (e.g., Tanaka 2009). One common feature of the models in these empirical studies is that the depreciation rate of consumption values is assumed to be common across

\footnotetext{
${ }^{3}$ Our modeling framework is also related to the previous literature on the dynamic purchase decisions in other consumer durable goods markets (e.g., Melnikov 2000, Song and Chintagunta 2003, Gordon 2009, Goettler and Gordon 2011, Carranza 2010, Gowrisankaran and Rysman 2011).
} 
potential buyers and product owners. This assumption is motivated by two challenges: (i) when physical depreciation is present, it is difficult to separately measure the decline of owners' consumption values due to satiation from that due to physical depreciation; (ii) even if researchers can control for physical depreciation, the consumption value depreciation for potential buyers (mainly due to how fresh the product is) can still be different from that for owners (mainly due to satiation). The data sets used in the previous studies only include variation in sales and prices of new and used goods. It lacks information on the quantities of used goods sold by consumers to retailers and the associated resale values, which are crucial for disentangling these two consumption value depreciation. These challenges have forced the previous studies to assume that consumption value depreciation is identical for product owners and potential buyers. In our study, we argue that by focusing on information/digital products (such as video games), we can rule out physical depreciation. Moreover, our new data set, which contains information on the quantities of used copies supplied by owners over time, allows us to relax this assumption.

Another important difference between our study and the previous studies is that we will estimate consumers' discount factor, instead of calibrating it according to the interest rate. As we will describe, our model implies that resale values of used copies provide exclusion restrictions that help identify the discount factor (Magnac and Thesmar 2002, Fang and Wang 2012). The intuition is that resale values do not affect consumers' current utility for buying decisions, but affect consumers' expected future payoffs. As a result, the observed correlation between sales of new video games and resale values can help recover the discount factor. Our identification strategy is similar to Chevalier and Goolsbee (2009), who study whether students are forward-looking in their textbook purchase decision. However, since they do not observe when and whether students sell their textbooks, they assume that all of them will sell it at the end of the semester, and the textbook resale value affects all students' utility for buying a new textbook if they are forwardlooking. While this assumption may be reasonable in the textbook market, the timing of selling used goods is endogenous in general. It should be highlighted that we endogenize the timing of selling used video game copies in this study. Furthermore, we observe how many owners sold their games to retailers and the cor- 
responding resale value. This allows us to model the expected future payoff from buying a video game as a function of not only the future resale value, but also the value of keeping the video game in the future. As a result, we have a richer framework to control for the impact of the resale value on buying decisions.

Also, this is the first paper that separately estimates the transaction costs for buying and selling used goods. Previous studies do not separately observe the quantities of used copies purchased and supplied by consumers and associated used-copy prices and resale values. Thus, they can estimate only one transaction cost (e.g., Chen et al. 2011, Schiraldi 2011). Our results show that these two transaction costs play different roles in influencing dynamic consumer buying and selling decisions.

There is also a large body of theoretical literature in economics and marketing. Theoretical papers in economics are mainly concerned with durability choice, pricing, the role of market frictions, etc. for durable goods monopolists (e.g., Swan 1970, Rust 1986, Bulow 1986, Anderson and Ginsburgh 1994, Waldman 1996, Hendel and Lizzeri 1999, Johnson 2011). In marketing, several papers examine a variety of marketing practices in new and used durable goods markets. These include leasing contracts (e.g., Desai and Purohit 1998, Desai and Purohit 1999), channel coordination (Desai et al. 2004, Shulman and Coughlan 2007), trade-ins (Rao et al. 2009), and retail versus P2P used goods markets (Yin et al. 2010). One common feature of these theoretical models is that they assume a market-clearing condition for used goods markets in every period. However, our data show that this assumption is far from a good approximation for the Japanese video game market - we consistently observe excess supply of used goods. Thus, our dynamic structural demand model will not impose a market-clearing condition. Instead, we will take advantage of the observed aggregate inventory of used copies and allow the transaction costs to depend on it (to capture the idea that it may reduce the search costs).

When our research is well under way, we learn another independent on-going work by Shiller (2012), who also investigates the interaction between new and used good demand, but in the U.S. video game industry. Due to the limited availability of used video game data in the U.S., he only examines online auction data for used goods transactions and scales it up by a factor of approximately forty in order to approximate the 
entire used goods market. As a result, his modeling approach and counterfactual experiment are different from ours in three important dimensions: First, he assumes that the resale value is the same as the used-copy price. Therefore, unlike our study, his model does not have any exclusion restrictions that can help identify the discount factor, and hence he calibrates it according to the interest rate. Second, since he does not observe the demand for and the supply of used copies in the regular retail market, he assumes a completely frictionless used good market, and that the used good market clears every period. In contrast, our data come from used goods transactions at retailers, which account for about $80 \%$ of the entire used goods market in Japan during our sample period. When retailers act as a middleman for used goods transactions, it is crucial to understand the role of transactions costs for both buying and selling decisions by using data on both quantities demanded and supplied for used goods, and the corresponding prices and resale values. In section 6 , we will discuss how transactions costs generate important dynamic patterns in both consumer buying and selling decisions. Finally, the U.S. and Japanese video game markets have adopted different pricing practices for new copies. As we will describe in the next section, Japanese video game publishers have historically been using flat-pricing for new copies. However, in the U.S., price skimming has been a common practice. As a result, Shiller's paper and ours investigate the optimal pricing implication for different pricing practices (price skimming versus flat pricing) in the counterfactual experiments where the used video game market is shut down. ${ }^{4}$

\section{Data}

\subsection{Japanese video game industry}

Since mid-80s, the Japanese video game market has grown rapidly. The size of the industry in 2009 has reached $\$ 5.5$ billion on a revenue basis (including sales of hardware, software, other equipments). This is about three times larger than the theatrical movie revenue in Japan, and it has become one of the most

\footnotetext{
${ }^{4}$ There are two other working papers which also study the video game markets using the structural modeling approach. Lee (2012) examines the impact of vertically integrated and exclusive software on industry structure and welfare in the U.S. video game industry. Zhou (2012) proposes a framework for studying dynamic pricing problems in a two-sided market, and applies it to the U.S. video game industry; she extends the estimation method proposed by Ishihara and Ching (2012) to estimate her model. Both studies abstract away the used video game market.
} 
important sectors in the Japanese entertainment industry. The existence of the used good market has been a serious issue for video game publishers since 90s. In 2009, the sales of used video games (software) alone amounts to $\$ 1.0$ billion on a revenue basis. One reason for the large used video game market in Japan could be that video game renting by third-party companies is prohibited by law in Japan. ${ }^{5}$ Another reason argued by Hirayama (2006) is the flat-pricing strategy commonly adopted by video game publishers - the price of new games is maintained at the initial level at least one year after the release. ${ }^{6}$ This may provide an opportunity for used goods market to grow and capture the segment of consumers who do not mind buying used goods. However, it can also be argued that the existence of the used market has induced publishers to adopt the flat-pricing strategy. Liang (1999) uses a theoretical model to show that when used goods markets are present, durable goods monopolists may be able to credibly commit to a high price (avoiding the Coase Conjecture). ${ }^{7}$ While investigating the optimality of the flat-pricing strategy is interesting, we will leave this topic for future research. Instead, we will take the flat pricing strategy as given, and focus on understanding consumers' dynamic buying and selling decision problem.

\subsection{Japanese video game data}

We have collected a data set of 20 video games that were released in Japan between 2004 and 2008. The data come from several sources. For each video game, weekly aggregate sales of new copies and its manufacturer suggested retail price (MSRP) are obtained from the weekly top 30 ranking published in Weekly Famitsu Magazine, a major weekly video game magazine in Japan published by Enterbrain, Inc. The average number of weeks observed across games is 19 weeks. In Japan, the sales of new copies sharply declines after the release week (see Figure 1). In our data set, the median percentage of new game copies sold in the release week (relative to the total annual sales for the first year) is $54 \%$, and the median percentage of new game copies sold within the first month (4 weeks) after release is $82 \%$. Thus, the sales of new copies is highly

\footnotetext{
${ }^{5}$ In principle, video game publishers can run the rental business for their own video games. However, only one publisher attempted to operate it in the history and did not succeed and exited.

${ }^{6}$ Note that in Japan, resale price maintenance is illegal for video games although it is legal for books, magazines, newspapers and music.

${ }^{7}$ The idea is similar to Ching (2010a) and Frank and Salkever (1992), who argue that endogenous market segmentation can allow brand-name firms to sustain a high price when facing entry of generic products in the prescription drug market.
} 
concentrated within the first month in Japan. In addition to the data from the primary market, we collected weekly aggregate trading volumes (both buying and selling) and the associated weekly average retail prices and resale values in the used market by game title. These are collected from the Annual Video Game Industry Report published by Media Create Co., Ltd. The average number of weeks observed across games is 36 weeks. According to an annual industry report by Enterbrain, Inc., about $80 \%$ of used video game trading occur at retailers during our sample period. Thus we do not consider the possibility such as online auctions for buying and selling used copies.

We also collected video game characteristics from Weekly Famitsu Magazine, including average critic and user rating, story-based game dummy, ${ }^{8}$ and multi-player game dummy. Finally, the potential size of market for a video game is measured by the installed base of the platform in which the video game was released. The platforms of the 20 games include three consoles (PlayStation 2, PlayStation 3, Nintendo GameCube). We collected the weekly sales of all three consoles above from their release week to calculate the cumulative sales.

Table 1 shows the summary statistics. The average price of used copies across games and time is about two-thirds of the price of a new copy. The average retailer markup for used copies is large: 1,687.2 in JPY or $73.0 \%$. This number is in contrast to the average retailer markup for new copies, which is around $10 \%$ (Tachibana 2006), and provides strong incentives for retailers to trade used copies. The average relative size of the used game market to the new game market, defined as the ratio of cumulative sales of used copies to that of new copies at the end of new-copy sales sample period, is 0.11 with a maximum of 0.29 and a minimum of 0.02. These numbers might appear small, but this is mainly because of the length of our sample. We observe the sales of new copies on average for 19 weeks, and the sales of used copies typically lasts longer than that of new copies beyond 19 weeks. If we had a longer time-series data set, we would expect the average ratio to be significantly larger than 0.11 . However, our data show that we have variation in the ratio. In particular, our data set contains video games with a very small used game market (the

\footnotetext{
${ }^{8}$ Story-based games (e.g., role-playing games) have an ending of the story, while non story-based games (e.g., sports games) have no clear definition for ending.
} 
minimum is $2 \%$ ). Thus, our parameters will not be estimated by data variation that are completely far from the counterfactual experiment situation, which is shutting down the used game market.

\subsection{Some empirical regularities}

In this section, we will discuss some new empirical regularities along three dimensions: (i) the quantities of used goods demanded and supplied over time, (ii) the inventory level of used goods over time, and (iii) the price and the resale value of used goods.

Figure 2 plots the average quantities of used copies demanded and supplied as well as the average inventory level of used copies over 15 weeks. The inventory level of used copies in week $t$ for a game is defined as the difference between the cumulative quantity of used copies supplied by consumers up to week $t-1$ and the cumulative quantity of used copies demanded by consumers up to week $t-1$.

First, both quantities of used copies demanded and supplied sharply increase in the first few weeks after the opening of the used game market (second week after release), reach their peaks, and gradually decrease afterwards. The initial increase is probably because it takes a few weeks for owners of a game to become satiated with their games. As the quantity of used copies supplied by owners increases, the sales of used copies also follows.

Second, on average, the inventory level of used copies carried by retailers grows in the first 15 weeks. About half of the games in our data set exhibit a decline after some point during the sample period. It is clear that in the Japanese video game market, the used market does not clear in every period. As mentioned earlier, unlike previous studies which assume the used goods market clears in each period, we will make use of this excess supply information when estimating our dynamic model. Also note that although retailers accumulate used-copy inventory, their buy-early-sell-late strategy still allows them to make positive profits due to a high markup.

Third, as shown in Figure 3, both the average price and resale value of used goods gradually decrease over time, and the resale value decreases slightly faster. This suggests that both potential buyers' and owners' consumption values depreciate over time, and their depreciation rates could be different. We will 
incorporate these features into our model.

\section{Model}

In this section, we present our dynamic discrete choice model of consumer buying and selling decisions for durable goods without physical depreciation. To make our presentation more concrete, we will describe our model in terms video games, as this is the market which we will study. We assume that consumers make buying and selling decisions separately for each game. ${ }^{9}$ Let $i$ indexes consumers, $g$ indexes games, and $t$ indexes time. To capture consumer heterogeneity, we allow discrete consumer types. At the beginning of the initial period $t=1$ (i.e., the period in which the new game is released), no consumers own game $g$ and used games are not available yet. Thus, consumers' decision problem is to decide whether to buy a new good or not to buy at all in $t=1$. In period $t>1$, consumers who have not bought the game up to $t-1$ observe the prices of new and used copies, the resale value and inventory level of used copies at retailers, and decide whether to buy a new or used good, or not to buy anything. Let $j=0,1,2$ denote no purchase option, new good purchase, and used good purchase, respectively. If consumers have already bought game $g$ prior to time $t$ and have not sold it yet, then they decide whether or not to keep the game given the resale value in period $t$. Let $k=0,1$ denote keeping and selling options, respectively. If consumers sell their game, they exit the market. Since video games will eventually become outdated, we assume a terminal period $t=T$ after which consumers can neither buy nor sell.

The state space of the consumer decision model consists of the following variables: (1) price of new and used goods $\left(p_{1}, p_{2}\right) ;(2)$ resale value $(r) ;(3)$ inventory level of used copies at retailers $(Y)$, which controls for the impact of the availability of used copies on consumer buying decisions; (4) time since release $(t)$, which characterizes the single-period consumption value to potential buyers; $(5)$ time since purchase $(\tau)$, which affects the single-period consumption value to owners; (6) unobserved demand shocks for new and

\footnotetext{
${ }^{9}$ We do not explicitly model the choice among different games because our focus is to study the choice between new and used copies of the same game title. We control for the impact of the availability of other games on the purchase decision of the focal game by including the cumulative number of other newly introduced games since game $g$ 's release. Note that Nair (2007) finds evidence that the substitutability between two different video games is very low in the US market, and consequently, he also does not model the choice among different games.
} 
used copies $\left(\xi_{1}, \xi_{2}\right) ;(7)$ unobserved supply shocks for used copies $\left(\xi_{s}\right)$; (8) cumulative number of newly introduced games since the release of the focal game $(C)$. As we will describe later, (1), (6), and (8) appear only in the consumer buying decision problem, (5) and (7) appear only in the consumer selling decision problem, and (2), (3) and (4) appear in both consumer buying and selling decision problems. We assume that consumers make their buying and selling decisions to maximize their total discounted expected utility for each game.

We will first describe the single-period utility functions for buying and selling decisions, and then move to the description of the value functions.

\subsection{Single-period utility functions}

In each period, consumers derive a value from owning game $g$ (consumption values). We assume that once consumers buy a game, they will derive the same consumption value regardless of whether it is a new copy or a used copy. This assumption is to capture the idea that the goods considered in this research have no physical depreciation. However, the decision to buy a used copy may be influenced by other factors such as the availability of used copies at retailers, psychological costs for using pre-owned goods, ${ }^{10}$ etc. Let $v^{g}(t, \tau)$ be a consumer's single-period consumption value of owning game $g$ at time $t$ if he has owned game $g$ for $\tau$ periods prior to time $t$. Note that if a consumer buys game $g$ at time $t$, he will receive $v^{g}(t, 0)$; if he/she keeps it at time $t+1$, he will receive $v^{g}(t+1,1)$. Later in this section, we will describe how we allow the two types of depreciation, freshness-based and satiation-based, to affect the consumption value over time. Finally, note that we assume that all consumers share a common consumption value.

Suppose that a consumer has not bought game $g$ up to time $t>1$. Consumer $i$ 's single-period utility for buying decisions at time $t$ is given by:

$$
u_{i j t}^{g}= \begin{cases}v^{g}(t, 0)-\alpha p_{1 t}^{g}+\xi_{1 t}^{g}+\rho D_{t}^{g}+\epsilon_{i 1 t}^{g} & \text { if buying a new copy }(j=1) \\ v^{g}(t, 0)-\alpha p_{2 t}^{g}-l_{Y}\left(Y_{t}^{g} ; \lambda_{i}\right)+\rho D_{t}^{g}+\xi_{2 t}^{g}+\epsilon_{i 2 t}^{g} & \text { if buying a used copy }(j=2) \\ l_{C}\left(C_{t}^{g} ; \pi\right)+\epsilon_{i 0 t}^{g} & \text { if no purchase }(j=0),\end{cases}
$$

where $p_{1 t}^{g}\left(p_{2 t}^{g}\right)$ is the price of new (used) copies of game $g$ at time $t ; \xi_{1 t}^{g}\left(\xi_{2 t}^{g}\right)$ is the unobserved demand

\footnotetext{
${ }^{10}$ Our assumption here is that once consumers overcome this psychological costs at the time of making a buying decision, then the consumption value they receive in subsequent periods is not affected by the psychological costs.
} 
shocks to new (used) copies; $\alpha$ is the price-sensitivity. As justified by the stylized facts discussed earlier, we assume that the price of new copies is constant over time, i.e., $p_{1 t}^{g}=p_{1}^{g}$ for all $t$, in our application to the Japanese video game market. We assume that $\xi_{1 t}^{g}\left(\xi_{2 t}^{g}\right)$ is i.i.d. across time and game, and is normally distributed with zero mean and the standard deviation $\sigma_{\xi_{j}}$ for $j=1,2 ; Y_{t}^{g}$ is the inventory level of used copies for game $g$ at retailers at the beginning of period $t . l_{Y}\left(Y_{t}^{g} ; \lambda_{i}\right)$ is the one-time transaction cost that consumers incur when buying a used good (search costs, psychological costs for pre-owned games, etc.), and $\lambda_{i}$ is a vector of parameters. In our empirical specification, we specify

$$
l_{Y}\left(Y_{t}^{g} ; \lambda_{i}\right)=\lambda_{0 i}+\lambda_{1} \exp \left(-\lambda_{2} Y_{t}^{g}\right)
$$

to capture the ideas that (i) consumers might be heterogeneous in psychological costs for pre-owned games $\left(\lambda_{0 i}\right)$ and (ii) search costs may depend on the availability of used copies captured by $\left(\lambda_{1}, \lambda_{2}\right)$. The heterogeneity in $\lambda_{0 i}$ is motivated by a consumer survey conducted by Enterbrain, Inc., which shows that about $15 \%$ of consumers never intend to purchase a used copy. ${ }^{11}$ This suggests that there is a segment of consumers who have high psychological costs of buying a used copy. This reduced form specification implies that when no used copies are available at the beginning of a period (i.e., $Y_{t}^{g}=0$ ), ${ }^{12}$ the cost is $\lambda_{0 i}+\lambda_{1}$. As the availability of used copies increases to infinity, the cost approaches $\lambda_{0 i}$ (if $\lambda_{2}>0$ ). Thus, if $\lambda_{1}$ and $\lambda_{2}$ are positive, the cost decreases as $Y_{t}^{g}$ increases; $D_{t}^{g}$ is a vector of seasonal dummies and $\rho$ captures the seasonal effects. ${ }^{13} C_{t}^{g}$ is the cumulative number of newly introduced games at time $t$ since the introduction of game $g$ (including the games released in the same week as game $g$ ); $l_{C}\left(C_{t}^{g} ; \pi\right)$ captures the competitive effect from other newly introduced games. In our application, it is specified as

$$
l_{C}\left(C_{t}^{g} ; \pi\right)=\pi_{0}+\pi_{1} \ln \left(C_{t}^{g}\right) .
$$

We assume that idiosyncratic errors, $\epsilon_{i j t}^{g}$, are i.i.d. across consumers and time, but allow it to be correlated across options $j$. We model the correlation in a nested logit framework. Let $\epsilon_{i j t}^{g}=\zeta_{i h t}^{g}+(1-\eta) v_{i j t}^{g}$

\footnotetext{
${ }^{11}$ Famitsu Game Hakusho 2006, page 217.

${ }^{12}$ Note that $Y_{t}^{g}=0$ does not mean that there are no used copies available for purchase in period $t$ because some owners would sell their copies to the market during the period.

${ }^{13}$ We include this variable only to control for the seasonal variation in sales and do not intend to study its impact on consumers' dynamic decision making. Thus, it is not included as a state variable.
} 
where $\zeta_{i h t}^{g}$ and $v_{i j t}^{g}$ are extreme value distributed, $h$ indexes nest and takes two possible values: $h=1$ groups the buying options (i.e., buying a new or used copy), and $h=0$ is the no purchase option. Thus, the consumer buying decision problem here is equivalent to a two-stage decision making where consumers first decide whether or not to buy, and if buying, then consumers choose a new or used copy. In this setup, the parameter $\eta \in[0,1)$ measures the within-nest correlation.

Next, consider consumers' selling decisions. Suppose that a consumer has bought game $g$ and kept it for $\tau$ periods. Consumer $i$ 's single-period utility for selling decisions at time $t$ is given by

$$
w_{i k t}^{g}(\tau)= \begin{cases}\alpha r_{t}^{g}-\mu_{i}+\xi_{s t}^{g}+e_{i 1 t}^{g} & \text { if selling to a retailer }(k=1) \\ v^{g}(t, \tau)+e_{i 0 t}^{g} & \text { if keeping the game }(k=0)\end{cases}
$$

where $r_{t}^{g}$ is the resale value of game $g$ at time $t ; \mu_{i}$ captures any additional cost of selling (transaction costs, endowment effects, etc.) and is allowed to depend on consumer type. This is again motivated by the same consumer survey by Enterbrain, Inc. which indicates that not all consumers sell their games; $\xi_{s t}^{g}$ is an i.i.d. unobserved shock to owners for selling decisions at time $t$. We assume it is normally distributed with zero mean and the standard deviation, $\sigma_{\xi_{s}} ; e_{i k t}^{g}$ is an idiosyncratic error, and we assume it is i.i.d. extreme value distributed across consumers and time.

For the single-period consumption value, $v^{g}(t, \tau)$, we will assume the following evolution over time. In the release period, we set $v^{g}(1,0)=\gamma^{g}$, where $\gamma^{g}$ is a game-specific constant. To capture the depreciation of potential buyers' consumption values due to the aging of a game (freshness-based depreciation), we allow $v^{g}(t, 0)$ to decay as a function of $t$. Specifically, we model the depreciation rate as: $v^{g}(t+1,0)=$ $(1-\varphi(t)) v^{g}(t, 0)$, where $\varphi(t)$ is a function of time trend. In our empirical application, we specify it as

$$
\varphi(t)=\frac{\exp \left(\phi_{1} \mathbb{I}(t=1)+\left(\phi_{2}+\phi_{3} \ln (t-1)\right) \mathbb{I}(t>1)\right)}{1+\exp \left(\phi_{1} \mathbb{I}(t=1)+\left(\phi_{2}+\phi_{3} \ln (t-1)\right) \mathbb{I}(t>1)\right)}
$$

where $\mathbb{I}(\cdot)$ is an indicator function. Note that we treat the depreciation from the first period to the second period differently from the rest of the periods. This is motivated by the observations that the sales of new copies from the release week to the second week usually suffers from a largest decline in the video game market. Next, we capture the depreciation of owners' consumption values due to satiation by modeling the 
depreciation rate as a function of product characteristics and the duration of ownership: $v^{g}(t+1, \tau+1)=$ $\left(1-\kappa\left(X_{g \tau}\right)\right) v^{g}(t, \tau)$, where $\kappa\left(X_{g \tau}\right)$ is a function of observed product characteristics and the duration of ownership. In the application, we use the following functional form:

$$
\kappa\left(X_{g \tau}\right)=\frac{\exp \left(X_{g \tau}^{\prime} \delta\right)}{1+\exp \left(X_{g \tau}^{\prime} \delta\right)}
$$

where $X_{g \tau}$ includes observed product characteristics of game $g$ (dummies for story-based games and multiplayer games, and average critic and user ratings) and the duration of ownership $(\tau)$.

Finally, we emphasize that our proposed model allows for consumer heterogeneity in the costs of buying $\left(\lambda_{0 i}\right)$ and selling $\left(\mu_{i}\right)$ a used copy. In addition, game owners are heterogeneous with respect to $(t, \tau)$ : owners' consumption value depends on when they bought the game and how long they have kept it. In general, we could allow for consumer heterogeneity in other preference parameters such as price-sensitivity, initial consumption value, etc. We have experimented several additional specifications and found that after controlling for consumer heterogeneity in $\left(\lambda_{0 i}, \mu_{i}\right)$, heterogeneity in other preference parameters does not play a significant role in explaining the observed sales pattern. We discuss some of those additional specifications as robustness checks in Section 6.2 and Appendix A.3.

\subsection{Value functions}

Since the dynamic consumer selling decision is nested within the dynamic consumer buying decision through the expected future payoff, we start off by describing the dynamic consumer selling decision, and then describe the dynamic buying decision. To simplify the notation, we will drop $g$ superscript. Also, let $\xi_{d}=\left(\xi_{1}, \xi_{2}\right)$ be the unobserved demand shocks (as opposed to $\xi_{s}$, the unobserved shocks for selling decisions), and $\beta$ be the discount factor common across consumers.

Let $s_{t, \tau}=\left(r_{t}, Y_{t}, \xi_{s t}, t, \tau\right)$ be the vector of state variables relevant to the selling decision problem. Note that other state variables $\left(p_{1 t}, p_{2 t}, C_{t}, \xi_{d t}\right)$ will not enter here. The inventory level, $Y_{t}$, is included since it could affect the distribution of the future resale value. Let $W_{i}\left(s_{t, \tau}\right)$ be the integrated value function (or Emax function) of the selling decision problem for consumer $i$, and $W_{i k}\left(s_{t, \tau}\right)$ be the corresponding 
alternative-specific value function of action $k$. The Bellman equation can be written recursively as:

$$
\begin{aligned}
W_{i}\left(s_{t, \tau}\right) & =E_{e} \max _{k \in\{0,1\}}\left\{W_{i k}\left(s_{t, \tau}\right)+e_{i k t}\right\}, \\
& =\ln \left\{\sum_{k \in\{0,1\}} \exp \left(W_{i k}\left(s_{t, \tau}\right)\right)\right\},
\end{aligned}
$$

where the second equality follows from the assumption that $e$ is type 1 extreme value distributed, and

$$
W_{i k}\left(s_{t, \tau}\right)= \begin{cases}\alpha r_{t}-\mu_{i}+\xi_{s t} & \text { if selling }(k=1), \\ v(t, \tau)+\beta E\left[W_{i}\left(s_{t+1, \tau+1}\right) \mid s_{t, \tau}\right] & \text { if keeping }(k=0) .\end{cases}
$$

The expectation in $E\left[W_{i}\left(s_{t+1, \tau+1}\right) \mid s_{t, \tau}\right]$ is taken with respect to the future resale value $\left(r_{t+1}\right)$, inventory level $\left(Y_{t+1}\right)$, unobserved shock for selling decision $\left(\xi_{s t+1}\right)$.

The probability of selling the game by consumer $i$ at $s_{t, \tau}$ is given by

$$
\operatorname{Pr}\left(k=1 \mid s_{t, \tau} ; i\right)=\frac{\exp \left(W_{i 1}\left(s_{t, \tau}\right)\right)}{\sum_{k^{\prime}=0}^{1} \exp \left(W_{i k^{\prime}}\left(s_{t, \tau}\right)\right)} .
$$

Next, consider the dynamic consumer buying decision. Let $b_{t}=\left(p_{1 t}, p_{2 t}, r_{t}, Y_{t}, C_{t}, \xi_{d t}, t\right)$ be the vector of state variables relevant to the buying decision problem. Let $V_{i}\left(b_{t}\right)$ be the integrated value function for consumer $i$ who has not bought the game prior to time $t$, and $V_{i j}\left(b_{t}\right)$ be the corresponding alternative-specific value functions of action $j$. The Bellman equation is given by

$$
\begin{aligned}
V_{i}\left(b_{t}\right) & =E_{\epsilon} \max _{j \in\{0,1,2\}}\left\{V_{i j}\left(b_{t}\right)+\epsilon_{i j t}\right\} \\
& =\ln \left\{\sum_{j \in\{0,1,2\}} \exp \left(V_{i j}\left(b_{t}\right)\right)\right\}
\end{aligned}
$$

where

$$
V_{i j}\left(b_{t}\right)= \begin{cases}v(t, 0)-\alpha p_{1 t}+\xi_{1 t}+\beta E\left[W_{i}\left(s_{t+1, \tau=1}\right) \mid s_{t, \tau=0}\right] & \text { new copy }(j=1), \\ v(t, 0)-\alpha p_{2 t}+\xi_{2 t}-l_{Y}\left(Y_{t} ; \lambda_{i}\right)+\beta E\left[W_{i}\left(s_{t+1, \tau=1}\right) \mid s_{t, \tau=0}\right] & \text { used copy }(j=2), \\ l_{C}\left(C_{t} ; \pi\right)+\beta E\left[V_{i}\left(b_{t+1}\right) \mid b_{t}\right] & \text { no purchase }(j=0) .\end{cases}
$$

The expectation in $E\left[V_{i}\left(b_{t+1}\right) \mid b_{t}\right]$ is taken with respect to the future prices of new and used copies $\left(p_{1 t+1}, p_{2 t+1}\right)$, resale value $\left(r_{t+1}\right)$, inventory level $\left(Y_{t+1}\right)$, cumulative number of competing games $\left(C_{t+1}\right)$, and unobserved shocks for buying decisions $\left(\xi_{d t+1}\right)$. It should be highlighted that the value function of the selling problem is embedded into the value function of the buying problem. ${ }^{14}$

\footnotetext{
${ }^{14}$ Note that the bellman equations stated here applies to $t>1$. The expected future payoffs component needs to be slightly modified for $t=1$ because $p_{2, t=1}$ and $r_{2, t=1}$ do not exist. We will discuss how to specify consumers' expectation about these state variables in the next section.
} 
The choice probability for option $j$ by consumer $i$ at $b_{t}$ is given by

$$
\operatorname{Pr}\left(j \mid b_{t} ; i\right)=\operatorname{Pr}\left(h=1 \mid b_{t} ; i\right) \cdot \operatorname{Pr}\left(j \mid h=1, b_{t} ; i\right)
$$

where

$$
\begin{aligned}
\operatorname{Pr}\left(h=1 \mid b_{t} ; i\right) & =\frac{\left[\sum_{j^{\prime}=1}^{2} \exp \left(\frac{V_{i j^{\prime}}}{1-\eta}\right)\right]^{1-\eta}}{\exp \left(V_{i 0}\right)+\left[\sum_{j^{\prime}=1}^{2} \exp \left(\frac{V_{i j^{\prime}}}{1-\eta}\right)\right]^{1-\eta}}, \\
\operatorname{Pr}\left(j \mid h=1, b_{t} ; i\right) & =\frac{\exp \left(\frac{V_{i j}}{1-\eta}\right)}{\sum_{j^{\prime}=1}^{2} \exp \left(\frac{V_{i j^{\prime}}}{1-\eta}\right)} .
\end{aligned}
$$

Given a finite time horizon, the value functions for both buying and selling decisions can be computed by backward induction from the terminal period, $T$. We assume that after the terminal period, consumers can neither buy or sell, but can continue enjoying the game if they have bought by the terminal period. We thus assume that consumers who own the game at the end of $t=T$ derive a terminal value equal to the present discounted value of future consumption values, taking satiation-based depreciation into account. In the empirical application, we approximate it by the present discounted value of consumption values for another 100 periods beyond the terminal period, and we set $T=100$.

\subsection{Aggregate sales}

Let $\psi_{l}$ be the population proportion of type- $l$ consumers and $\sum_{l=1}^{L} \psi_{l}=1$. In order to derive the aggregate demand for new and used copies, and aggregate volume of used copies sold to retailers by owners, we need to derive the evolution of the size of each consumer type. Let $M_{l t}^{d}$ be the size of type- $l$ consumers who have not bought the video game. It evolves according to

$$
M_{l t+1}^{d}=M_{l t}^{d}\left(1-\sum_{j=1}^{2} \operatorname{Pr}\left(j \mid b_{t} ; l\right)\right)+N_{l t+1},
$$

where $N_{l t+1}$ is the size of new type- $l$ consumers who enter the market at time $t+1$. We assume that the proportion of new type- $l$ consumers follows the population proportion, $\psi_{l} \cdot{ }^{15}$

\footnotetext{
${ }^{15}$ Therefore, we can use the total installed base of the corresponding game console in the release week to calibrate $N_{l, t=1}$. For $t>1, N_{l t}$ can be calibrated based on the weekly sales of the corresponding game console.
} 
Next, let $M_{l t}^{s}(\tau)$ be the size of type- $l$ consumers who have bought and owned the game for $\tau$ periods at time $t$. It evolves according to

$$
M_{l t+1}^{s}(\tau)= \begin{cases}M_{l t}^{d} \sum_{j=1}^{2} \operatorname{Pr}\left(j \mid b_{t} ; l\right) & \text { if } \tau=1, \\ \left.M_{l t}^{s}(\tau-1) \cdot \operatorname{Pr}\left(k=0 \mid s_{t, \tau-1} ; l\right)\right) & \text { if } 1<\tau \leq t\end{cases}
$$

The aggregate observed demand at state $b_{t}$ is then

$$
Q_{j}^{d}\left(b_{t}\right)=\sum_{l=1}^{L} M_{l t}^{d} \operatorname{Pr}\left(j \mid b_{t} ; l\right)+\varepsilon_{j t}
$$

where $j=1$ is new copies and $j=2$ is used copies, and $\varepsilon_{j t}$ represents a measurement error. The aggregate observed quantity supplied to retailers by consumers at state $s_{t}=s_{t, \tau} \backslash\{\tau\}$ is given by

$$
Q^{s}\left(s_{t}\right)=\sum_{l=1}^{L} \sum_{\tau=1}^{t-1} M_{l t}^{s}(\tau) \operatorname{Pr}\left(k=1 \mid s_{t, \tau} ; l\right)+\varepsilon_{s t},
$$

where $\varepsilon_{s t}$ represents a measurement error.

\section{Estimation Strategy}

The estimation of consumer preference parameters is carried out in two steps (e.g., Rust 1987, Hendel and Nevo 2006, Erdem et al. 2003). In the first step, we recover the evolution processes of used game prices, resale values, inventory levels, and cumulative number of newly introduced games from the data. ${ }^{16}$ In the second step, these estimated processes will be used to form consumers' expectation about future price of used goods, resale value, inventory level, cumulative number of newly introduced games, and then we estimate the rest of the structural parameters.

In the first step, we estimate the consumer expectation processes as follows. For $t>2$, we model the processes of the price of used goods and the resale value to be a function of own lagged value, the lagged inventory level and game characteristics; we also model the processes of the inventory level to be functions of its lagged value and game characteristics; For $t=2$, this approach cannot be applied because the lagged values of used price and resale value do not exist (recall that $t=1$ is the initial period). We therefore assume that the initial price and resale value of used copies are functions of the price of new copies and

\footnotetext{
${ }^{16}$ We assume that consumers expect the price of new copies to remain constant over time.
} 
game characteristics. We should also note that $Y_{t=1}=Y_{t=2}=0$. Finally, we assume that the cumulative number of newly introduced games to be a function of its lagged value. The estimation results based on all 20 video games are reported in Tables 2 and $3{ }^{17}$

In the second step, we estimate the dynamic discrete choice model with a finite time horizon. Notice that the price of used goods and resale value may be correlated with unobserved shocks. We employ a new Bayesian MCMC algorithm for non-stationary finite-horizon DDP models proposed by Ishihara and Ching (2012), and combine it with the pseudo-policy function approach in Ching (2010b) to control for the potential endogeneity problems.

\subsection{Bayesian Dynamic Programming Algorithm}

Recently, Imai et al. (2009) develop a new Bayesian estimation algorithm which has the potential to significantly cut down the computational burden of estimating stationary discrete choice dynamic programming (DDP) problems. ${ }^{18}$ The key innovation of the IJC algorithm is that instead of fully solving for the fixed point of the Bellman operator in each outer loop, it gradually solves for it by applying the Bellman operator only once per outer loop iteration, and uses the set of partially-solved value functions (pseudo-value functions) from the past outer loop iterations for nonparametrically approximating expected value functions. Ishihara and Ching (2012) argue that if the dynamic model has multiple continuous state variables, IJC's idea for estimating DDP models with continuous state variables (see Section 3.2 of Imai et al. 2009) can be extended to help reduce the computational burden of computing the expected future payoffs even for non-stationary finite-horizon DDP models. The main idea behind their algorithm for continuous state variables is to compute pseudo-value functions at one randomly drawn state in each iteration and store them. The set of past pseudo-value functions used in approximating the expected future payoffs will then be evaluated at different state points. Thus, one can simply adjust the weight given to each of the past pseudo-value function by the transition density from the current state to the state at which the past pseudo-value function is evaluated.

\footnotetext{
${ }^{17}$ We estimate the process for the cumulative number of newly introduced games separately for each of the 20 games. The results are not reported here, but are available upon request.

${ }^{18}$ Ching et al. (2012) provide a step-by-step guide for implementing the IJC algorithm.
} 
The new algorithm proposed by Ishihara and Ching (2012) has three main features: (1) pseudo-value functions are computed and stored for each time period, (2) in each MCMC iteration and in each time period, pseudo-value functions are computed only at one randomly drawn vector of continuous state variables by backward induction, and (3) expected value functions at time $t$ are approximated using the set of pseudovalue functions at time $t+1$. Unlike other approximation approaches (e.g., Keane and Wolpin 1994, Rust 1997), in which value functions need to be computed at a set of pre-determined grid points in all periods, the new algorithm computes pseudo-value functions at only one randomly drawn state point in each period and the expectation of the future payoffs with respect to the continuous state variables can simply be done by the weighted average of past pseudo-value functions. Thus, it reduces the per iteration computational time dramatically, and has the potential to reduce the overall estimation burden. We describe the details of the estimation procedure for our model in Appendix A.1.

\subsection{Pseudo-policy function approach}

The price and resale value of used games could be endogenous. To address this issue, we follow the pseudopolicy function (PPF) approach proposed by Ching (2010b). This approach is similar to other limited information approaches (e.g., Villas-Boas and Winer 1999, Park and Gupta 2009, Petrin and Train 2010), but differs in that it approximates the pricing policy as a function of observed and unobserved state variables of the equilibrium model. This has the potential of generating a more flexible joint distribution of $(p, q){ }^{19}$ In our model, the state space of the equilibrium model includes unobserved shocks $\left(\xi_{1 t}, \xi_{2 t}, \xi_{s t}\right)$, consumption values $(v(t, \tau))$, inventory level $\left(Y_{t}\right)$, cumulative number of newly introduced games $\left(C_{t}\right)$, the size of potential buyers $\left(M_{l t}^{d}\right)$, and the size of owners for each each duration of ownership $\left(M_{l t}^{s}(\tau)\right)$. Furthermore, we include seasonal dummies for Golden Week $\left(D_{1 t}\right)$ and Christmas $\left(D_{2 t}\right) \cdot{ }^{20}$ After experimenting several functional

\footnotetext{
${ }^{19}$ This approach can also be applied to control for the potential endogeneity of advertising/detailing (e.g., Ching and Ishihara 2010; 2012b), and individual retailers' pricing (e.g., Gu and Yang 2011).

${ }^{20}$ Golden Week in Japan refers to a week in late April and early May that involves multiple public holidays.
} 
forms, we decided to use the following specification for the price of used goods (for $t \geq 2$ ):

$$
\begin{aligned}
\ln p_{2 t}= & \omega_{p 0}+\omega_{p 1} v(t, 0)+\omega_{p 2} \frac{1}{(t-1)} \sum_{\tau=1}^{t-1} v(t, \tau)+\omega_{p 3} \xi_{1 t}+\omega_{p 4} \xi_{2 t}+\omega_{p 5} \xi_{s t} \\
& +\omega_{p 6} \frac{1}{L} \sum_{l=1}^{L} M_{l t}^{d}+\omega_{p 7} \frac{1}{L(t-1)} \sum_{l=1}^{L} \sum_{\tau=1}^{t-1} M_{l t}^{s}(\tau)+\omega_{p 8} Y_{t}+\omega_{p 9} C_{t}+\omega_{p 10} D_{1 t}+\omega_{p 11} D_{2 t}+\nu_{p t}
\end{aligned}
$$

where $\nu_{p t}$ is the prediction error. Also, the pseudo-policy function for the resale value is specified as (for $t \geq 2):$

$$
\begin{aligned}
\ln r_{t}= & \omega_{r 0}+\omega_{r 1} v(t, 0)+\omega_{r 2} \frac{1}{(t-1)} \sum_{\tau=1}^{t-1} v(t, \tau)+\omega_{r 3} \xi_{1 t}+\omega_{r 4} \xi_{2 t}+\omega_{r 5} \xi_{s t} \\
& +\omega_{r 6} \frac{1}{L} \sum_{l=1}^{L} M_{l t}^{d}+\omega_{p 7} \frac{1}{L(t-1)} \sum_{l=1}^{L} \sum_{\tau=1}^{t-1} M_{l t}^{s}(\tau)+\omega_{r 8} Y_{t}+\omega_{r 9} C_{t}+\omega_{r 10} D_{1 t}+\omega_{r 11} D_{2 t}+\nu_{r t},
\end{aligned}
$$

where $\nu_{r t}$ is the prediction error.

Note that $C_{t}$, which is the cumulative number of newly introduced games since the release of the focal game, could play the role of an instrument. This is because publishers usually pre-announce game release dates several months in advance and copies of games are manufactured before the release week. Thus the pre-announced release date is rarely postponed based on the aggregate shocks in the release week. Thus, we expect $C_{t}$ to be uncorrelated with $\xi_{t}$ 's. However, $C_{t}$ would likely affect $p_{2 t}$ and $r_{t}$. On one hand, $C_{t}$ could influence $p_{2 t}$ because it affects the demand for used copies of the focal game. On the other hand, $C_{t}$ could affect $r_{t}$ because owners of the focal game may be attracted to newly introduced games and choose to sell the focal game, which affect the supply of used copies of the focal game. Moreover, $Y_{t}$, which is the retailers' inventory level of used games at retailers at the beginning of period $t$, could also play the role of an instrument if $\xi_{t}$ is $i . i . d .{ }^{21}$ It is plausible that the price and resale value of used games at time $t$ depend on the inventory level, $Y_{t}$. Inclusion of $Y_{t}$ and $C_{t}$, which are exogenous at time $t$ in our model, should help reduce the reliance on functional form restrictions for identification.

Assuming the normal distributions for measurement errors in the sales of new and used copies as well as the quantities sold by consumers to retailers, and prediction errors in the pseudo-pricing policy functions, we derive the joint likelihood of the demand-side model and the pseudo-policy functions, which will be used

\footnotetext{
${ }^{21}$ Even if $\xi_{t}$ is serially correlated, $Y_{t}$ should be relatively uncorrelated with $\xi_{t}$ because it is a cumulative measure.
} 
to compute the acceptance probabilities in the Metropolis-Hastings algorithm. Appendix A.2 describes the construction of the likelihood function.

\section{Remarks}

Note that if consumers observe all the state variables and understand how the equilibrium prices are generated, then one would gain efficiency by using the pseudo-policy functions to form the consumers' future price expectations as well. However, we decided not to take this approach for the following reasons. First of all, it is unclear if consumers are aware of all the state variables of the equilibrium model, especially, the size of potential buyers (i.e., $\left.M_{l t}^{d}\right)$ and the sizes of owners (i.e., $\left\{M_{l t}^{s}(\tau)\right\}_{\tau=1}^{t-1}$ ), which are "hidden" and not available in any public domain. It seems more plausible that consumers use a simpler Markov process to forecast future prices and resale value based on what are observed in the public domain, which include current prices, resale value and game characteristics, as these variables are much more salient. In particular, Hendel and Nevo (2006) argue that a simple Markov process might be a reasonable assumption about consumers' memory and formation of expectations. Février and Wilner (2009) provide evidence to support such an approach. Besides, if one uses the pseudo-policy functions to form the consumer price expectation, one needs to specify the state space for the dynamic consumer buying and selling decision model to include $\left(M_{l t}^{d},\left\{v(t, \tau), M_{l t}^{s}(\tau)\right\}_{\tau=1}^{t-1}\right)$. Such a modification will dramatically increase the number of continuous state variables compared to our current approach, and thus make the model infeasible to estimate.

\subsection{Identification}

In this section, we provide an informal discussion for the identification of our proposed model. To facilitate our discussion, we first describe the identification when there is no heterogeneity in the costs of buying and selling a used copy (i.e., $\lambda_{0 l}=\lambda_{0}$ and $\mu_{l}=\mu$ for all $l$ ). We then discuss what data variation helps us identify the heterogeneity.

We first consider the price sensitivity $(\alpha)$, the impact of used-copy inventory on the costs for buying a used copy $\left(\lambda_{0}, \lambda_{1}, \lambda_{2}\right)$, and the competitive effect $\left(\pi_{1}\right)$ in $l_{C}\left(C_{t}^{g} ; \pi\right)$. These are identified by variation in the sales of new and used copies, and the variation in used-copy prices, used-copy inventory, and the number 
of competing games, respectively. The within-group correlation $(\eta)$ is identified by the extent to which the conditional market share of new (or used) copies is correlated with the unconditional market share of new (or used) copies (Berry 1994).

The game-specific constant $\left(\gamma^{g}\right)$ is identified by the level of sales over time for each game. The freshnessbased depreciation rate ( $\varphi$ 's), which are common across games, is identified by the "average" declining rate of sales of new games over time. Given $\gamma^{g}, \varphi^{\prime}$ s and $\alpha$, the parameters that determine the satiation-based depreciation rate $(\delta$ 's) and the cost of selling $(\mu)$ are identified by the variation in the volume of video games sold by consumers to retailers over time across games (note that $\delta$ is a function of game characteristics).

The identification of the discount factor $(\beta)$ hinges crucially on exclusion restrictions, by which we mean the existence of at least one variable which affects the future payoffs, but does not affect the current utility of buying used and new games (Chevalier and Goolsbee 2009, Fang and Wang 2012). ${ }^{22}$ In our model, the resale value $\left(r_{t}^{g}\right)$ plays exactly this role because it does not enter the current period utility and consumers only use its current value to predict its value next period, which gives them the expected return of selling the game next period. Therefore, the extent to which the sales of new and used copies are affected by the resale value provides us with information about how consumers discount the future.

So far we have assumed that there is no consumer heterogeneity. Now we consider how the heterogeneity parameters $\left(\lambda_{0 l}, \mu_{l}\right)$ and the proportion of each consumer type $\left(\psi_{l}\right)$ are identified. To simplify the argument, assume that there are two types of consumers and the model has only two periods. Furthermore, it will be useful to ignore the idiosyncratic errors $(\epsilon, e)$ in the utility functions. Let's first consider the heterogeneity in the cost of buying a used copy $\left(\lambda_{0 l}\right)$ (for now, we assume that $\mu_{l}$ 's are fixed at some values). We will explain how the intertemporal substitution pattern helps identify $\lambda_{0 l}$. Without loss of generality, assume that $\lambda_{01}>\lambda_{02}$. We should note that in the first period, consumers only have two options: buying a new copy, or wait; in the second period, they can also choose to buy a used copy. Note further that the price of new copies is constant over time, and the used-copy price is always lower than the new-copy price. If

\footnotetext{
${ }^{22}$ Chung et al. (2011), Lee (2012), and Ching and Ishihara (2012a) also explore such exclusion restrictions to identify the discount factor in different applications. Magnac and Thesmar (2002) discuss another exclusion restriction that is closely related.
} 
consumers are homogeneous and buy the video game, then we should see either (i) they all buy a new copy in the first period, or (ii) they all buy a used copy in the second period. Only a model with heterogeneous consumers can generate sales of new copies (in period 1) and used copies (in period 2). So the relative sales of new and used copies provides us with some information about the extent of consumer heterogeneity. In particular, the reason why a consumer chooses to buy a used copy in the second period is because his/her expected utility of buying a used copy is higher than the utility of buying a new copy in the first period. Therefore, given our assumption of $\lambda_{01}>\lambda_{02}$, the consumers who buy a used copy in the second period must be type 2 (and consumers who buy a new copy in the first period must be type 1 ). Since we assume that $\left(\lambda_{0 l}, \mu_{l}, \psi_{l}\right)$ are the same across games, the cross-sectional variation in the observed prices and sales of new copies in the first period, and the observed prices and sales of used copies in the second period allow us to identify $\left(\lambda_{01}, \lambda_{02}\right)$ and the proportion of each consumer type $\left(\psi_{1}, \psi_{2}\right)$.

Given $\left(\lambda_{0 l}, \psi_{l}\right)$, let's consider the identification of $\mu_{l}$. We now need to extend the model to three periods. Note that consumers who purchased in period 1 (they are type 1) are also the potential suppliers of used copies in period 2. Therefore, the cross-sectional variation in the observed quantity of used copies supplied in period 2 allows us to pin down their selling costs, $\mu_{1}$. Similarly, consumers who buy a used copy in period 2 (they are type 2) are the potential suppliers of used copies in period 3. Hence, the cross-sectional variation in the quantity of used copies supplied in period 3 allows us to identify their selling costs, $\mu_{2}$.

Our identification arguments for consumer heterogeneity only make use of three periods of data. But certainly, the data variation beyond these three periods also helps identify the heterogeneity parameters. Finally, note that the extreme value error terms (or any idiosyncratic error terms with continuous distribution) make the demand and used-copy supply become a smooth function of parameters. So even if we add them back to the model, the main idea of our identification argument still applies. Under this environment, both types of consumers will buy new copies in period 1, and used copies in period 2. But the consumers who buy new (used) copies are still mainly type 1 (2). Therefore, the cross-sectional data variation in the first three periods (and the cross-sectional and time-series variation in the subsequent periods) still provides 
us with many over-identification restrictions to identify the heterogeneity parameters.

\section{Results}

\subsection{Parameter Estimates}

We allow for two types of consumers who differ in their costs of buying and selling at used goods retailers (i.e., $\lambda_{0 l}$ and $\mu_{l}$ ). The estimation results are reported in Table 4 . We report the posterior mean and standard deviation (s.d.). We estimate two versions; in one version (demand-only model), we do not control for the potential price endogeneity using the pseudo-policy function approach. In another version (full model), we control for the price endogeneity. We find that the estimates are qualitatively similar in these two versions. Below, we will mainly discuss the estimates of the full model.

Based on the posterior s.d., all of the parameters are tightly estimated and have the expected signs. The estimated discount factor is 0.902 . Recall that the unit of periods in our application is a week. Our estimate is much lower than the discount factor calibrated from the weekly interest rate $(\simeq 0.999)$, which is typically done in the literature (note that most dynamic models do not have exclusion restrictions to help identify the discount factor). However, our result is consistent with the previous studies in experimental/behavioral economics (see Frederick et al. 2002 for a survey on this literature), and three recent empirical studies (Yao et al. 2012, Lee 2012, Chung et al. 2011) which also find that the discount factor is lower than the interest rate. Price-sensitivity $(\alpha)$ is positive because it enters the utility function as a negative term. Its magnitude is small because price are in JPY ( $1 \mathrm{JPY} \simeq 0.01 \mathrm{US}$ dollar).

As for the cost of buying a used copy $\left(\lambda_{0 l}, \lambda_{1}, \lambda_{2}\right)$, recall that we use the following functional form: $l_{Y}\left(Y_{t}^{g} ; \lambda_{L}\right)=\lambda_{0 l}+\lambda_{1} \exp \left(-\lambda_{2} Y_{t}^{g}\right)$. Both $\lambda_{1}$ and $\lambda_{2}$ are positive, indicating that the cost of buying a used copy diminishes as the inventory level rises. This is intuitive because as the availability of used copies increases, consumers' search costs may decrease. We quantify the range of the cost of buying a used copy in a monetary term by dividing $l_{Y}$ by the price coefficient - it falls in $[743,5,890]$ in JPY for type- 1 consumers and $[8,882,14,029]$ in JPY for type- 2 consumers. ${ }^{23}$ The results suggest that type- 1 consumers are the main

\footnotetext{
${ }^{23}$ The minimum number represents the cost when $Y_{t}^{g} \rightarrow \infty$, and the maximum represents the cost when $Y_{t}^{g}=0$.
} 
purchaser of used copies. Indeed, as we will show below, the cost of buying a used copy for type-2 consumers is so high that they hardly purchase used copies. Note that the estimated proportion of type-1 consumers is 0.846 (and that of type- 2 consumers is 0.154 ). Interestingly, the proportion of type-2 consumers (who hardly purchase used copies) is consistent with the survey we described earlier in the model section (Famitsu Game Hakusho 2006): about $15 \%$ of respondents in the survey reported that they never intend to purchase a used game. We also find a significant difference in the selling costs between these two types. Type-1 consumers' cost is about three times larger than that of type- 2 consumers, suggesting that type- 2 consumers are the main supplier of used copies.

We find that both the Golden Week and Christmas season have a positive impact on sales, but the magnitude is larger for the Christmas season. The parameter for the competitive effect from other games $\left(\pi_{1}\right)$ is positive, suggesting that the increasing number of new game introduction may make it less attractive for consumers to buy the focal game.

Parameters for the freshness-based depreciation rate include two intercepts $\left(\phi_{1}, \phi_{2}\right)$ and a time effect $\left(\phi_{3}\right)$. The estimated depreciation rate from the first to the second week (captured via $\left.\phi_{1}\right)$ is about $21 \%$, and that from the second to third week (captured via $\phi_{2}$ ) is $5 \%$. It becomes close to zero after the third week (captured by $\phi_{3}$, which is very negative). These results are consistent with the observed pattern of the sales of new copies, which declines quickly during the first few weeks after release.

For the depreciation rate of owners' consumption values due to satiation, we include the following product characteristics in $X_{g \tau}$ : an intercept, story-based game dummy, multi-player game dummy, average critic and user rating, and duration of ownership. A positive coefficient of a variable implies that the variable will increase the depreciation rate. Our estimates suggest that on average, multi-player games exhibit a higher depreciation rate. On the other hand, story-based games, and games with a higher user rating exhibit a lower depreciation rate. Depending on product characteristics, the weekly depreciation rate for owners at $\tau=1$ ranges from $69 \%$ to $86 \%$. Finally, the coefficient for the duration of ownership suggests that the per-period depreciation rates become lower as consumers keep the game longer. 
The parameters for pseudo-policy functions are reported in Table 5. In particular, we find that both unobserved demand shocks to new and used copies $\left(\omega_{p 3}, \omega_{p 4}, \omega_{r 3}, \omega_{r 4}\right)$ have a small and non-significant impact on both used-copy price and resale value, but unobserved shocks to selling $\left(\omega_{p 5}, \omega_{r 5}\right)$ have a negative and significant impact on both price and resale value of used copies. Note that the unobserved shocks to selling affects the resale value negatively and the resale value affects the selling utility positively. Therefore, we expect that the price coefficient would be biased downwards if we did not control for the endogeneity problem. This downward bias is indeed what we find from the comparison of the price coefficients between the full and demand-only models. However, the difference is relatively small (2.95e-04 versus 2.64e-04), suggesting that the price endogeneity problem does not appear to be of first-order importance in the Japanese video game market.

\subsection{Goodness-of-fit and Robustness Checks}

Our estimated dynamic model provides a good fit to the data. To show the goodness-of-fit, we simulate the sales of new and used copies as well as the volume sold to retailers by consumers by drawing 1,000 sets of parameters (including unobserved shocks) from the posterior distribution, computing the predicted quantities, and averaging them over 1,000 draws. Figures 4-6 show the fit of (1) new-copy sales, (2) usedcopy sales, (3) volume sold to retailers by consumers, respectively, for all 20 games based on our estimates of the full model. In general, our dynamic model is able to fit the data very well even with only two types of consumers. Similarly, we also simulate the predicted price and resale value of used copies by the pseudopricing policy functions. Figures 7-8 show the fit of (1) used-copy price and (2) resale value, respectively, for all 20 games. These results show that the pseudo-pricing policy functions specified in Equations (19) and (20) are also able to capture the data trend quite well.

Finally, to check the robustness of our model specification, we estimate six additional specifications: (i) allow for heterogeneity only in price-sensitivity; (ii) allow for heterogeneity both in transaction costs and in price-sensitivity; (iii) allow for heterogeneity both in transaction costs and satiation-based depreciation; (iv) allow for a correlation between demand shocks for new and used copies; (v) allow for the effect of used-copy 
inventory on the utility function for no purchase option so as to capture the possibility that a high inventory level might signal low game quality; (vi) assume that consumers are myopic. We find that these alternative models either produce worse fit (specification (i) and (vi)), or similar fit (specifications (ii)-(v)) compared with the specification focused here. In Appendix A.3, we report the estimates and discuss the results in more detail.

\subsection{Roles of Heterogeneity in Transaction Costs}

Having recovered two latent classes of consumers, we investigate how the heterogeneity in transaction costs generates different buying and selling decisions across consumer types. We use our simulation results to compute the average proportion of (1) new-copy sales, (2) used-copy sales, (3) volume of used copies supplied by owners, by consumer type. The results are reported in Table 6 . Recall that $85 \%$ of the population is type 1. Yet, the new-copy sales by type- 1 consumers is only around $68-70 \%$ because they have a lower cost of buying used games. In addition, more than $90 \%$ of used-copy sales are generated by type- 1 consumers and more than $99 \%$ of used copies are supplied by type- 2 consumers. These patterns arise because our model and the data pick up two important segments of consumers: type-1 segment captures consumers who are willing to buy a used copy and do not bother selling at all, and type-2 segment captures consumers who purchase a new copy and consider selling. ${ }^{24}$

Next, we investigate the role of heterogeneity in the relative market share of used to new copies. The relative market share is important for understanding the degree to which used copies are competing with new copies. If the relative market share is large for used copies, the elimination of the used game market could help increase the sales of new copies significantly due to the substitution effect. The last two columns of Table 6 report the relative choice probability of used to new copies. They reveal that by the fifth week, type-1 consumers buy more used copies than new copies (the relative market share is greater than one). However, since type-2 consumers have a high cost for buying a used copy, their relative market share remains

\footnotetext{
${ }^{24}$ One may wonder if heterogeneity in price-sensitivity could generate these two segments that explain the data well. It turns out that heterogeneity in price-sensitivity alone is not sufficient for producing a good fit to the data. Furthermore, we estimate a model with heterogeneity in both transaction costs and price-sensitivity and find that there is very little heterogeneity in price-sensitivity. We discuss these in more details in Appendix A.3.
} 
well below one even by the fifteenth week. These findings suggest that if the used good market is shut down, the increase in the sales of new copies mainly comes from type-1 consumers.

\subsection{Elasticities}

This section discusses elasticities of demand and supply based on the estimates of the full model. The crossprice elasticity of demand between used and new copies will inform us whether they are close substitutes from consumers' viewpoint (e.g. Ghose et al. 2006). Moreover, our dynamic model is able to quantify (i) the inventory elasticities of demand, and (ii) the price elasticities of used-copy supply, i.e., volume sold to retailers by consumers. Previous studies were unable to measure these two types of elasticities because they do not observe (i') the inventory of used copies, and (ii') the quantities supplied of used copies and associated resale values. Our results for these two elasticities may shed some light on why retailers accumulate used-copy inventory for future sales instead of procuring just enough for their current period sales.

Table 7 shows seven types of elasticities labeled by E.1-E.7. E.1-E.4 examine the price elasticities of demand. E.1 and E.2 investigate the percentage change in the sales of new and used copies in week $t$ in response to a $1 \%$ change in new-copy price in week $t$, while E. 3 and E.4 show the percentage change in the sales of new and used copies in response to a $1 \%$ change in used-copy price. Our primary focus here is on E.2 and E.3, which show the cross-price elasticity of demand for new and used copies, respectively. Our estimates show that the cross-price elasticities are generally very small for both new and used-copy demand, suggesting that new and used copies are poor substitutes in Japan. This result might be surprising to video game publishers who believe that new and used copy should be highly substitutable because they are basically identical products. However, our analysis identifies two important elements in transactions costs that differentiate used copies from new copies: heterogeneity in the fixed portion of transactions costs $\left(\lambda_{0 l}\right)$ and the availability of used copies captured by used-copy inventory $\left(\lambda_{1}, \lambda_{2}\right)$. Heterogeneity in transaction costs indicates that there are consumers who do not view new and used copies as identical. Specifically, type-2 consumers in our model hardly purchase used copies due to a high (fixed) cost for buying a used copy. For these consumers, new and used copies are very poor substitutes. On top of the heterogeneity, 
used-copy inventory also plays an important role in differentiating used copies from new copies. Even type-1 consumers, who have a low (fixed) cost for buying a used copy, will find it costly to buy a used copy when the availability of used copies is very low in the earlier product lifecycle. Later this section, we will examine the inventory elasticity of demand for used copies and discuss the importance of used-copy availability for used-copy demand.

We investigate the cross substitution pattern further by examining among those who switch away from used copies due to a $1 \%$ increase in used-copy price, how many percent of them actually switch to new copies rather than to no purchase. In Table 8, we show the proportion of switchers who buy new copies and its breakdown by consumer type over time. We find that in the second week where used copies just become available, only $12 \%$ of those who switch away from used copies buy new copies and the rest of them switch to no purchase. As time goes on, the proportion diminishes to about $4 \%$. This is partly because the outside option becomes more attractive over time through an increase in the number of newly introduced competing games. This provides further evidence that used games are not good substitute for new games.

E.5 and E.6 of Table 7 show the inventory elasticities of demand, i.e., the percentage change in the sales of new and used copies due to a $1 \%$ change in the inventory of used copies. We find that in the first few weeks where not many used copies are available, a $1 \%$ increase in the inventory has a large effect on the demand for used copies. This suggests that the availability of used copies could be playing an important role in increasing the sales of used copies by reducing the cost for buying a used copy.

Finally, E.7 examines the elasticity of used-copy volume supplied to retailers by consumers. Note that due to a high selling cost, type-1 consumers hardly sell their video games. Moreover, most of type-2 consumers' new-copy purchases occur in the earlier weeks. Thus, as more type-2 consumers sell, the proportion of type- 2 owners shrinks, which causes the elasticity of supply of used-copy to decrease over time. This pattern also suggests one possible reason why retailers accumulate used-copy inventory in the earlier stage of product lifecycle - it becomes harder for them to procure used copies in the later part of product lifecycle as game owners become more inelastic with respect to the resale value. 


\subsection{Elimination of the Used Game Market}

Video game publishers often claim that the existence of the used game market lowers the sales of new games. The claim is often based on the conjecture that if there were no used game market, most of the used copies buyers would switch to a new copy. However, our cross-price elasticity of demand indicates that this concern is likely unimportant in Japan. On the other hand, the used game market serves as a place for consumers to sell games that they no longer want to keep. If the used game market is shut down, it is possible that the demand for new copies may drop because the total expected discounted value from buying a new copy could be lowered due to the lack of selling opportunities. To find out whether it is worthwhile for video game publishers to pursue the strategy to shut down the used game market, we will use our estimated model to conduct a counterfactual experiment.

We first keep the prices of new copies at the observed values even after the elimination of the used game market and examine the change in the quantity of new copies demanded. In general, the optimal price of new copies in the absence of the used game market could be very different from the observed prices in the data. Thus, we compute the optimal flat-prices of new copies when there is no used game market. In computing the optimal flat-price for each game, we set the marginal cost at JPY 1,000 (Tachibana 2006). We maintain the flat-pricing scheme because it has been an industry practice in Japan, and there might be some obstacles for the industry to shift to the price-skimming scheme.

Based on the simulation, we compute the statistics on the average percentage change in video game publishers' profits for a game due to the elimination of the used game market. Table 9 summarizes the results. We first discuss the scenario where we maintain the prices of new copies at the currently observed prices. The average profits across games decline by $10 \%$, with only one game exhibits an increase in profits. This finding suggests that the future selling opportunity plays an important role in determining consumers' buying decisions. To further investigate this conjecture, we plot the average percentage change in new-copy sales across games for the first 15 weeks in Figure 9. It shows that the change in the sales of new copies is negative in the first several weeks after release, and then it becomes positive afterwards. However, the 
sales of new copies is so high in the first several weeks that an increase in the sales in the later weeks does not compensate the loss in the sales in the first several weeks, resulting in a reduction in total profits. The initial decline is due to the lowered future value from buying for type- 2 consumers: when the resale value is still high, type-2 consumers' buying decision is critically influenced by the future selling opportunity. While the percentage changes for type- 2 consumers are consistently negative in the first 15 weeks, the magnitude becomes smaller over time and this is due to a decline in resale value. The increasing trend of the percentage change for the aggregate sales is also motivated by the increasing trend in the percentage change for type-1 consumers. Recall that in Table 6, we saw that the relative market share of used to new copies for type-1 was increasing over time. After the elimination of the used game market, the type- 1 consumers who used to buy a used copy in later weeks switch to new copies. Also, note that since type-1 consumers seldom sell, they are not affected by the eliminated selling opportunity. Thus the percentage change for type-1 consumers is consistently positive in the first 15 weeks.

To quantify the value of having the future selling opportunity, we compute the change in continuation payoffs from buying today due to the elimination of the used game market. ${ }^{25}$ We further monetize the change by the estimated price-coefficient. Figure 10 shows the value of having the future selling opportunity for each type. As expected, the average value for type- 1 consumers is close to zero because most of them do not sell even when the used game market is present. For type-2, the average value of having the future selling opportunity is about JPY 3,300 in the release week, and slowly declines over time.

Note that we have assumed that the observed flat-prices remain unchanged so far. If we allow video game publishers to adjust the price of new copies optimally after the used game market is shut down, the results reported above would likely change. Thus, we compute the optimal flat-prices and then examine changes in profits under the optimal flat-prices. We find that the optimal flat-prices are on average $33 \%$ lower than the observed prices. Publishers' average profits per game increases by $18.6 \%$ due to the elimination of the used game market. This counterfactual result provides an important implication for recent pricing practices for digital distribution of video games. One can view our counterfactual experiment to be close to having

\footnotetext{
${ }^{25}$ We thank Mitchell Lovett for suggesting this exercise.
} 
publishers completely switch to the digital downloading format, which will essentially shut down the used game market. Thus, the results of this counterfactual experiment should be able to shed some light on the profitability of this marketing strategy.

\section{Conclusion}

Based on our newly collected data set from the Japanese new and used video game markets, we develop a new empirical framework for studying consumers dynamic buying and selling decisions. Our framework, together with this unique data set, allows us to estimate the discount factor, the depreciation rates of potential buyers' and owners' consumption values separately, and the transactions costs for buying and selling used goods separately. We find that our estimated model is able to fit the dynamic patterns of buying and selling decisions very well.

Our estimation results suggest that consumers in the Japanese video game market are forward-looking, and there are two important segments of consumers who differ in their transaction costs for buying and selling used copies. In contrast to the conventional belief, our parameter estimates imply that new and used video games are not close substitute in Japan. We also compute two new elasticities, inventory elasticity of usedcopy demand and elasticity of used-copy supply, which have not been studied before. Our counterfactual experiment suggests that the resale effect plays an important role in generating new-copy sales: without adjusting the price of a new copy optimally, video game publishers are likely to lose profits by shutting down the used game market. However, if publishers can adjust the price optimally, the elimination of the used game market is beneficial to publishers.

This paper does not explicitly model the supply-side competition between video game publishers and used game retailers. While this is a limitation, the current approach is suitable for our research purpose for two reasons. First, it avoids potential biases due to the mis-specification of the supply-side competitive structure. Second, since our interest is to examine the impact of eliminating the used game market on video game publishers' profits relative to the current situation, our counterfactual scenarios do not require us to model the competition between new game publishers and used game retailers. However, if we combine 
our demand-side model with a supply-side model, we will be able to address some additional research questions. For example, our estimated elasticities suggest that if the opening of the used game market were delayed by several weeks, it could avoid the competition from used copies, and yet maintain the future selling opportunity for consumers. This remedy was actually proposed during the used video game lawsuit in Japan, but was not adopted. To examine the impact of this policy, we need to model the supply-side competition between new game publishers and used game retailers.

In relation to this, one should also be careful when interpreting the results of our counterfactual exercises. Although we find that the average profits of the games we examined could increase after eliminating the used game market, we do not know if the game publishers are setting their prices optimally in the current situation. To investigate this, we would also need a model of used good retailers, so that we can predict how the used-copy prices will react to any changes of the new-copy prices. Finally, the accumulation of aggregate inventory of used copies over time is another puzzling fact that requires more research. We plan to study these important research topics in the future. 


\section{References}

Anderson, Simon P., Victor A. Ginsburgh. 1994. Price Discrimination via Second-Hand Markets. European Economic Review 38(1) 23-44.

Berry, Steven, James Levinsohn, Ariel Pakes. 1995. Automobile Prices in Market Equilibrium. Econometrica 63(4) 841-890.

Berry, Steven T. 1994. Estimating Discrete-Choice Models of Product Differentiation. RAND Journal of Economics 25(2) 242-262.

Bulow, Jeremy. 1986. An Economic Theory of Planned Obsolescence. Quarterly Journal of Economics 101(4) $729-750$.

Carranza, Juan Esteban. 2010. Product Innovation and Adoption in Market Equilibrium: The Case of Digital Cameras. International Journal of Industrial Organization 28(6) 604-618.

Chen, Jiawei, Susanna Esteban, Matthew Shum. 2011. How Much Competition is a Secondary Market. Working Paper, Department of Economics, University of California, Irvine.

Chevalier, Judith, Austan Goolsbee. 2009. Are Durable Goods Consumers Forward Looking? Evidence from the College Textbook Market. Quarterly Journal of Economics 124(4) 1853-1884.

Ching, Andrew, Susumu Imai, Masakazu Ishihara, Neelam Jain. 2012. A Practitioner's Guide to Bayesian Estimation of Discrete Choice Dynamic Programming Models. Quantitative Marketing and Economics 10(2) 151-196.

Ching, Andrew, Masakazu Ishihara. 2010. The Effects of Detailing on Prescribing Decisions under Quality Uncertainty. Quantitative Marketing and Economics 8(2) 123-165.

Ching, Andrew, Masakazu Ishihara. 2012a. Identification of Dynamic Models of Reward Programs. Working Paper, Rotman School of Management, University of Toronto.

Ching, Andrew, Masakazu Ishihara. 2012b. Measuring the Informative and Persuasive Roles of Detailing on Prescribing Decisions. Management Science 58(7) 1374-1387.

Ching, Andrew T. 2010a. A Dynamic Oligopoly Structural Model for the Prescription Drug Market After Patent Expiration. International Economic Review 51(4) 1175-1207.

Ching, Andrew T. 2010b. Consumer Learning and Heterogeneity: Dynamics of Demand for Prescription Drugs After Patent Expiration. International Journal of Industrial Organization 28(6) 619-638.

Chung, Doug J., Thomas Steenburgh, K. Sudhir. 2011. Do Bonuses Enhance Sales Productivity? A Dynamic Structural Analysis of Bonus-Based Compensation Plans. Working Paper, Yale School of Management.

Desai, Preyas, Oded Koenigsberg, Devavrat Purohit. 2004. Strategic Decentralization and Channel Coordination. Quantitative Marketing and Economics 2(1) 5-22.

Desai, Preyas, Devavrat Purohit. 1998. Leasing and Selling: Optimal Marketing Strategies for a Durable Goods Firm. Management Science 44(11) S19-S34.

Desai, Preyas, Devavrat Purohit. 1999. Competition in Durable Goods Markets: The Strategic Consequences of Leasing and Selling. Marketing Science 18(1) 42-58.

Dube, Jean-Pierre H., Gunter J. Hitsch, Pradeep K. Chintagunta. 2010. Tipping and Concentration in Markets with Indirect Network Effects. Marketing Science 29(2) 216-249. 
Engers, Maxim, Monica Hartmann, Steven Stern. 2009. Annual Miles Drive Used Car Prices. Journal of Applied Econometrics 24(1) 1-33.

Erdem, Tulin, Susumu Imai, Michael P. Keane. 2003. Brand and Quantity Choice Dynamics Under Price Uncertainty. Quantitative Marketing and Economics 1(1) 5-64.

Esteban, Susanna, Matthew Shum. 2007. Durable-Goods Oligopoly with Secondary Markets: The Case of Automobiles. RAND Journal of Economics 38(2) 332-354.

Fang, Hanming, Yang Wang. 2012. Estimating Dynamic Discrete Choice Models with Hyperbolic Discounting, with an Application to Mammography Decisions. Working Paper, Department of Economics, University of Pennsylvania.

Fevrier, Philippe, Lionel Wilner. 2009. Do Consumers Correctly Expect Price Reductions? Working paper, CREST.

Frank, Richard G., David S. Salkever. 1992. Pricing, Patent Loss and the Market for Pharmaceuticals. Southern Economic Journal 59(2) 165-179.

Frederick, Shane, George Loewenstein, Ted O'Donoghue. 2002. Time Discounting and Time Preference: A Critical Review. Journal of Economic Literature 40(2) 351-401.

Ghose, Anindya, Michael D. Smith, Rahul Telang. 2006. Internet Exchange for Used Books: An Empirical Analysis of Product Cannibalization and Welfare Impact. Information System Research 17(1) 3-19.

Goettler, Ronald, Brett R. Gordon. 2011. Does AMD spur Intel to innovate more? Forthcoming in Journal of Political Economy.

Gordon, Brett. 2009. A Dynamic Model of Consumer Replacement Cycles in the PC Processor Industry. Marketing Science 28(5) 846-867.

Gowrisankaran, Gautam, Marc Rysman. 2011. Dynamics of Consumer Demand for New Durable Goods. Working Paper, Department of Economics, Boston University.

Gu, Zheyin (Jane), Sha Yang. 2011. Consumer Attribute-Based Learning and Retailer Category Management Strategies. Working Paper, State University of New York, Albany.

Hendel, Igal, Alessandro Lizzeri. 1999. Interfering with Secondary Markets. RAND Journal of Economics 30(1) $1-21$.

Hendel, Igal, Aviv Nevo. 2006. Measuring the Implications of Sales and Consumer Inventory Behavior. Econometrica 74(6) 1637-1673.

Hirayama, Taro. 2006. A Sequel to the Used Game Lawsuit. Research Center for the Legal System of Intellectual Property Column .

Imai, Susumu, Neelam Jain, Andrew Ching. 2009. Bayesian Estimation of Dynamic Discrete Choice Models. Econometrica 77(6) 1865-1899.

Ishihara, Masakazu, Andrew Ching. 2012. Bayesian Estimation of Non-Stationary Discrete Choice Dynamic Programming Models. Working Paper, Stern School of Business, New York University.

Johnson, Justin P. 2011. Secondary Markets with Changing Preferences. RAND Journal of Economics 42(3) 555-574. 
Keane, Michael P., Kenneth I. Wolpin. 1994. The Solution and Estimation of Discrete Choice Dynamic Programming Models by Simulation and Interpolation: Monte Carlo Evidence. Review of Economics and Statistics 76(4) 648-672.

Lee, Robin S. 2012. Vertical Integration and Exclusivity in Platform and Two-Sided Markets. Working Paper, Stern School of Business, New York University.

Liang, Meng-Yu. 1999. Does a Second-Hand Market Limit a Durable Goods Monopolist's Market Power? Working Paper, University of Wisconsin-Madison.

Liu, Hongju. 2010. Dynamics of Pricing in the Video Game Console Market: Skimming or Penetration? Journal of Marketing Research 47(3) 428-443.

Magnac, Thierry, David Thesmar. 2002. Identifying Dynamic Discrete Decision Processes. Econometrica $\mathbf{7 0}(2)$ 801-816.

Melnikov, Oleg. 2000. Demand for Differentiated Products: The Case of the U.S. Computer Printer Market. Working Paper, Department of Economics, Yale University.

Musalem, Andrés, Eric T. Bradlow, Jagmohan S. Raju. 2009. Bayesian Estimation of Random-Coefficients Choice Models using Aggregate Data. Journal of Applied Econometrics 24(3) 490-516.

Nair, Harikesh. 2007. Intertemporal Price Discrimination with Forward-Looking Consumers: An Application to the US Market for Console Video-Games. Quantitative Marketing and Economics 5(3) 239-292.

Park, Sungho, Sachin Gupta. 2009. Simulated Maximum Likelihood Estimator for the Random Coefficient Logit Model Using Aggregate Data. Journal of Marketing Research 46(4) 531-542.

Petrin, Amil, Kenneth Train. 2010. A Control Function Approach to Endogeneity in Consumer Choice Models. Journal of Marketing Research 47(1) 3-13.

Purohit, Devavrat. 1992. Exploring the Relationship between the Markets for New and Used Durable Goods: The Case of Automobiles. Marketing Science 11(2) 154-167.

Rao, Raghunath Singh, Om Narasimhan, George John. 2009. Understanding the Role of Trade-Ins in Durable Goods Markets: Theory and Evidence. Marketing Science 28(5) 950-967.

Rust, John. 1986. When is it Optimal to Kill Off the Market for Used Durable Goods? Econometrica 54(1) 65-86.

Rust, John. 1987. Optimal Replacement of GMC Bus Engines: An Empirical Model of Harold Zurcher. Econometrica 55(5) 999-1033.

Rust, John. 1997. Using Randomization to Break the Curse of Dimensionality. Econometrica 65(3) 487-516.

Schiraldi, Pasquale. 2011. Automobile Replacement: a Dynamic Structural Approach. RAND Journal of Economics 42(2) 266-291.

Shiller, Benjamin. 2012. Digital Distribution and the Prohibition of Resale Markets for Information Goods. Working Paper, Department of Economics, Brandeis University.

Shulman, Jeffrey D., Anne T. Coughlan. 2007. Used Goods, Not Used Bads: Profitable Secondary Market Sales for a Durable Goods Channel. Quantitative Marketing and Economics 5(2) 191-210.

Song, Inseong, Pradeep K. Chintagunta. 2003. A Micromodel of New Product Adoption with Heterogeneous and Forward-Looking Consumers: Application to the Digital Camera Category. Quantitative Marketing and Economics 1(4) 371-407. 
Swan, Peter L. 1970. Durability of Consumption Goods. American Economic Review 60(5) 884-894.

Tachibana, Hiroki. 2006. Shuwasystem Industry Trend Guide Book: Video Game Industry (written in Japanese). Shuwasystem, Tokyo, Japan.

Tanaka, Migiwa. 2009. Deflation in Durable Goods Markets: an Empirical Model of the Tokyo Condominium Market. Working Paper, Department of Economics, Hong Kong University of Science and Technology.

Tedeschi, Bob. 2004. Online Battle of Low-Cost Books. The New York Times (July 12).

Villas-Boas, J. Miguel, Russell S. Winer. 1999. Endogeneity in Brand Choice Models. Management Science 45(10) 1324-1338.

Waldman, Michael. 1996. Durable Goods Pricing When Quality Matters. Journal of Business 69(4) 489-510.

Yang, Sha, Yuxin Chen, Greg M. Allenby. 2003. Bayesian Analysis of Simultaneous Demand and Supply. Quantitative Marketing and Economics 1(3) 251-275.

Yao, Song, Carl F. Mela, Jeongwen Chiang, Yuxin Chen. 2012. Determining Consumers' Discount Rates With Field Studies. Journal of Marketing Research 49(6) 822-841.

Yin, Shuya, Saibal Ray, Haresh Gurnani, Animesh Animesh. 2010. Durable Products with Multiple Used Goods Markets: Product Upgrade and Retail Pricing Implications. Marketing Science 29(3) 540-560.

Zhou, Yiyi. 2012. Failure to Launch in Two-Sided Markets: A Study of the U.S. Video Game Market. Working Paper, State University of New York, Stony Brook. 
Table 1: Summary statistics

\begin{tabular}{lcccc} 
& Average & S.D. & Min & Max \\
\hline \hline Price of new copies (in JPY) & $7,613.1$ & 629.1 & 7,140 & 9,240 \\
Price of used copies (in JPY) & $4,515.3$ & $1,087.8$ & 2,219 & 7,433 \\
Resale value of used copies (in JPY) & $2,828.1$ & $1,182.7$ & 1,036 & 6,547 \\
Markup for used copies (in JPY) & $1,687.2$ & 382.2 & 435 & 2,786 \\
Markup for used copies (\%) & $73.0 \%$ & $36.5 \%$ & $7.3 \%$ & $210.7 \%$ \\
Weekly sales of new copies & $100,650.4$ & $259,022.3$ & 2,772 & $2,236,881$ \\
Weekly sales of used copies & $7,184.6$ & $6,478.8$ & 458 & 62,734 \\
Ratio of cumulative sales of used to new copies & 0.107 & 0.063 & 0.021 & 0.286 \\
Weekly quantity sold by consumers & $8,121.4$ & $8,436.8$ & 1,012 & 55,830 \\
Weekly inventory of used copies & $31,022.5$ & $28,347.7$ & 0 & 129,462 \\
Market size (installed base) & $14,866,067.6$ & $6,097,167.2$ & 746,971 & $20,822,775$ \\
Weekly \# new game introduction & 7.01 & 4.02 & 0 & 17 \\
Dummy for story-based games & 0.700 & 0.470 & 0 & 1 \\
Dummy for multi-player games & 0.450 & 0.510 & 0 & 1 \\
Critic rating (in 10-point scale) & 8.99 & 0.656 & 7.75 & 10 \\
User rating & 56.4 & 9.20 & 41.6 & 67.4 \\
\hline Ne: USD I JPY l00 & & & & \\
\hline
\end{tabular}

Note: USD $1 \approx$ JPY 100

* user rating is a standardized score against a set of video games released in the same year (by Enterbrain, Inc.) 
Table 2: Regressions for the price of used games and resale value $(t=2)$

\begin{tabular}{lcccc} 
& \multicolumn{2}{c}{ price of used copies } & \multicolumn{2}{c}{ resale value } \\
variable & estimate & s.e. & estimate & s.e. \\
\hline \hline price of new copies & $0.784^{*}$ & 0.083 & 0.839 & 0.129 \\
dummy for story-based games & 208.9 & 114.9 & 100.5 & 177.8 \\
dummy for multi-player games & 150.1 & 120.3 & 140.4 & 186.2 \\
critic rating & 127.0 & 85.5 & 132.4 & 132.3 \\
user rating & -12.8 & 6.31 & -13.4 & 9.76 \\
constant & -548.2 & 732.2 & -1899.6 & 1133.2 \\
\hline Adjusted R-squared & \multicolumn{2}{c}{0.921} & \multicolumn{3}{c}{0.840} \\
\# observations & \multicolumn{2}{c}{20} \\
\hline
\end{tabular}

Note: $*$ p $<0.05$

Table 3: Regressions for the price of used games, resale value, and inventory level $(t>2)$

price of used copies resale value inventory

\begin{tabular}{lcccccc} 
variable & estimate & s.e. & estimate & s.e. & estimate & s.e. \\
\hline \hline lagged value & $0.958^{*}$ & 0.005 & $0.928^{*}$ & 0.005 & $0.958^{*}$ & 0.006 \\
lagged inventory & $-2.22 \mathrm{E}-03^{*}$ & $2.39 \mathrm{E}-04$ & $-1.71 \mathrm{E}-03^{*}$ & $2.45 \mathrm{E}-04$ & - & - \\
dummy for story-based games & 5.44 & 16.5 & -26.6 & 16.8 & $1581.9^{*}$ & 472.5 \\
dummy for multi-player games & -18.1 & 17.4 & -14.3 & 17.7 & -470.7 & 497.4 \\
critic rating & $29.0^{*}$ & 10.8 & $28.0^{*}$ & 11.0 & $1214.4^{*}$ & 306.8 \\
user rating & $-2.26^{*}$ & 0.731 & -0.876 & 0.744 & $-93.8^{*}$ & 20.85 \\
constant & 54.6 & 97.8 & -14.6 & 97.3 & -4376.2 & 2733.4 \\
\hline Adjusted R-squared & \multicolumn{2}{c}{0.987} & \multicolumn{2}{c}{0.988} & \multicolumn{2}{c}{0.984} \\
\# observations & \multicolumn{2}{c}{647} & \multicolumn{2}{c}{647} \\
\hline
\end{tabular}

Note: $* \mathrm{p}<0.05$ 
Table 4: Demand estimates

\begin{tabular}{|c|c|c|c|c|}
\hline & \multicolumn{2}{|c|}{ full model } & \multicolumn{2}{|c|}{ demand-only model } \\
\hline & mean & s.d. & mean & s.d. \\
\hline \multicolumn{5}{|l|}{ preference parameters } \\
\hline discount factor $(\beta)$ & 0.902 & 0.001 & 0.907 & 0.001 \\
\hline price sensitivity $(\alpha)$ & $2.95 \mathrm{E}-04$ & $6.52 \mathrm{E}-06$ & $2.61 \mathrm{E}-04$ & $8.39 \mathrm{E}-06$ \\
\hline \multicolumn{5}{|l|}{ costs for buying a used copy } \\
\hline intercept for type-1 $\left(\lambda_{01}\right)$ & 0.219 & 0.047 & 0.237 & 0.051 \\
\hline intercept for type- $2\left(\lambda_{02}\right)$ & 1.74 & 0.128 & 1.54 & 0.151 \\
\hline inventory level & & & & \\
\hline coefficient $\left(\lambda_{1}\right)$ & 2.40 & 0.016 & 2.33 & 0.012 \\
\hline adjustment parameter $\left(\lambda_{2}\right)$ & 4.71E-04 & $1.03 \mathrm{E}-05$ & 5.32E-04 & $2.19 \mathrm{E}-05$ \\
\hline \multicolumn{5}{|l|}{ costs for selling a used copy } \\
\hline type-1 $\left(\mu_{1}\right)$ & 9.90 & 0.093 & 9.61 & 0.076 \\
\hline type- $2\left(\mu_{2}\right)$ & 1.98 & 0.061 & 2.44 & 0.046 \\
\hline \multicolumn{5}{|l|}{ seasonal dummies } \\
\hline golden week (early May) $\left(\gamma_{1}\right)$ & 0.052 & 0.008 & 0.054 & 0.014 \\
\hline christmas (late Dec.) $\left(\gamma_{2}\right)$ & 0.273 & 0.005 & 0.238 & 0.008 \\
\hline \multicolumn{5}{|l|}{ outside options } \\
\hline intercept $\left(\pi_{0}\right)$ & 0.315 & 0.035 & 0.288 & 0.044 \\
\hline competitive effect $\left(\pi_{1}\right)$ & 0.200 & 0.007 & 0.174 & 0.010 \\
\hline \multicolumn{5}{|l|}{ depreciation rates } \\
\hline \multicolumn{5}{|l|}{ potential buyers } \\
\hline $1^{\text {st }}$-week intercept $\left(\phi_{1}\right)$ & -1.33 & 0.062 & -1.14 & 0.075 \\
\hline $2^{\text {na }}$-week intercept $\left(\phi_{2}\right)$ & -2.97 & 0.217 & -2.65 & 0.165 \\
\hline time since $3^{\text {ra }}$ week (logged) $\left(\phi_{3}\right)$ & -9.51 & 0.135 & -10.5 & 0.150 \\
\hline \multicolumn{5}{|l|}{ game owners } \\
\hline intercept $\left(\delta_{0}\right)$ & 1.74 & 0.015 & 1.71 & 0.030 \\
\hline story-based $\left(\delta_{1}\right)$ & -0.633 & 0.012 & -0.625 & 0.016 \\
\hline multi-player $\left(\delta_{2}\right)$ & 0.281 & 0.011 & 0.246 & 0.016 \\
\hline critic rating $\left(\delta_{3}\right)$ & -0.005 & 0.007 & 0.001 & 0.005 \\
\hline user rating $\left(\delta_{4}\right)$ & -0.004 & 0.001 & 0.001 & 0.001 \\
\hline ownership duration (logged) $\left(\delta_{5}\right)$ & -0.542 & 0.007 & -0.633 & 0.017 \\
\hline proportion of type-1 consumers $\left(\psi_{1}\right)$ & 0.846 & 0.009 & 0.819 & 0.010 \\
\hline \multicolumn{5}{|l|}{ parameters for error terms } \\
\hline within-group correlation $(\eta)$ & 0.093 & 0.008 & 0.054 & 0.011 \\
\hline \multicolumn{5}{|l|}{ s.d.(measurement error) } \\
\hline sales new $\left(\varepsilon_{1}\right)$ & 84983.5 & 8540.7 & 82656.8 & 7470.0 \\
\hline sales used $\left(\varepsilon_{2}\right)$ & 3143.7 & 142.3 & 2821.7 & 122.2 \\
\hline volume sold by consumers $\left(\varepsilon_{\mathrm{s}}\right)$ & 2071.9 & 123.0 & 1202.7 & 99.9 \\
\hline \multicolumn{5}{|l|}{ s.d.(unobserved aggregate shocks) } \\
\hline sales new $\left(\xi_{1}\right)$ & 0.679 & 0.095 & 0.512 & 0.070 \\
\hline sales used $\left(\xi_{2}\right)$ & 0.234 & 0.029 & 0.217 & 0.022 \\
\hline volume sold by consumers $\left(\xi_{s}\right)$ & 0.144 & 0.009 & 0.186 & 0.009 \\
\hline
\end{tabular}

Note: 20 game-specific intercepts $\left(\gamma^{\mathrm{g}}\right)$ are estimated but not reported here. 
Table 5: Estimates for pseudo-pricing policy functions

\begin{tabular}{|c|c|c|}
\hline & mean & s.d. \\
\hline \multicolumn{3}{|l|}{ pseudo-pricing policy function parameters } \\
\hline \multicolumn{3}{|l|}{ price of used copies } \\
\hline intercept $\left(\omega_{\mathrm{p} 0}\right)$ & 8.16 & 0.021 \\
\hline consumption value to potential buyers $\left(\omega_{\mathrm{p} 1}\right)$ & 0.030 & 0.005 \\
\hline avg. consumption value to owners $\left(\omega_{\mathrm{p} 2}\right)$ & 0.330 & 0.037 \\
\hline unobserved shock to buying new copy $\left(\omega_{\mathrm{p} 3}\right)$ & -0.003 & 0.007 \\
\hline unobserved shock to buying used copy $\left(\omega_{\mathrm{p} 4}\right)$ & $-1.20 \mathrm{E}-04$ & 0.019 \\
\hline unobserved shock to selling $\left(\omega_{\mathrm{p} 5}\right)$ & -1.55 & 0.132 \\
\hline avg. size of potential buyers $\left(\omega_{\mathrm{p} 6}\right)$ & $-7.70 \mathrm{E}-09$ & 7.09E-10 \\
\hline avg. size of owners $\left(\omega_{\mathrm{p} 7}\right)$ & $1.50 \mathrm{E}-07$ & $1.83 \mathrm{E}-07$ \\
\hline inventory of used goods $\left(\omega_{\mathrm{p} 8}\right)$ & $-2.33 \mathrm{E}-06$ & 3.39E-07 \\
\hline cumulative \# competing games $\left(\omega_{\mathrm{p} 9}\right)$ & 0.001 & $1.39 \mathrm{E}-04$ \\
\hline golden week seasonal dummy $\left(\omega_{\mathrm{p} 10}\right)$ & 0.137 & 0.040 \\
\hline christmas seasonal dummy $\left(\omega_{\mathrm{p} 11}\right)$ & -0.073 & 0.038 \\
\hline s.d. $\left(v_{\mathrm{pt}}\right)$ & 0.087 & 0.007 \\
\hline \multicolumn{3}{|l|}{ resale value of used copies } \\
\hline intercept $\left(\omega_{\mathrm{r} 0}\right)$ & 6.92 & 0.091 \\
\hline consumption value to potential buyers $\left(\omega_{\mathrm{r} 1}\right)$ & 0.145 & 0.013 \\
\hline avg. consumption value to owners $\left(\omega_{\mathrm{r} 2}\right)$ & 0.490 & 0.061 \\
\hline unobserved shock to buying new copy $\left(\omega_{\mathrm{r} 3}\right)$ & -0.003 & 0.008 \\
\hline unobserved shock to buying used copy $\left(\omega_{\mathrm{r} 4}\right)$ & 0.001 & 0.021 \\
\hline unobserved shock to selling $\left(\omega_{\mathrm{r} 5}\right)$ & -1.97 & 0.134 \\
\hline avg. size of potential buyers $\left(\omega_{\mathrm{r} 6}\right)$ & $2.47 \mathrm{E}-08$ & $6.03 \mathrm{E}-10$ \\
\hline avg. size of owners $\left(\omega_{\mathrm{r} 7}\right)$ & $-1.08 \mathrm{E}-07$ & $2.11 \mathrm{E}-07$ \\
\hline inventory of used goods $\left(\omega_{\mathrm{r} 8}\right)$ & $-4.20 \mathrm{E}-06$ & 4.42E-07 \\
\hline cumulative \# competing games $\left(\omega_{\mathrm{r} 9}\right)$ & $-4.62 \mathrm{E}-04$ & 4.17E-05 \\
\hline golden week seasonal dummy $\left(\omega_{\mathrm{r} 10}\right)$ & 0.152 & 0.047 \\
\hline christmas seasonal dummy $\left(\omega_{\mathrm{r} 11}\right)$ & -0.023 & 0.042 \\
\hline s.d. $\left(v_{\mathrm{rt}}\right)$ & 0.100 & 0.007 \\
\hline
\end{tabular}


Table 6: Proportion of Predicted Quantities and Relative Market Share by Consumer Type

\begin{tabular}{|c|c|c|c|c|c|c|c|c|}
\hline \multirow{2}{*}{$\begin{array}{c}\text { weeks } \\
\text { in release }\end{array}$} & \multicolumn{2}{|c|}{$\begin{array}{c}\text { sales of } \\
\text { new copies }\end{array}$} & \multicolumn{2}{|c|}{$\begin{array}{c}\text { sales of } \\
\text { used copies }\end{array}$} & \multicolumn{2}{|c|}{$\begin{array}{c}\text { volume sold } \\
\text { to retailers }\end{array}$} & \multicolumn{2}{|c|}{$\begin{array}{c}\text { relative market share of } \\
\text { used to new copy }\end{array}$} \\
\hline & type 1 & type 2 & type 1 & type 2 & type 1 & type 2 & type 1 & type 2 \\
\hline 1 & 0.677 & 0.323 & & & & & & \\
\hline 2 & 0.674 & 0.326 & 0.903 & 0.097 & 0.003 & 0.997 & 0.082 & 0.018 \\
\hline 3 & 0.674 & 0.326 & 0.902 & 0.098 & 0.003 & 0.997 & 0.407 & 0.091 \\
\hline 4 & 0.675 & 0.325 & 0.901 & 0.099 & 0.003 & 0.997 & 0.852 & 0.194 \\
\hline 5 & 0.677 & 0.323 & 0.902 & 0.098 & 0.003 & 0.997 & 1.09 & 0.247 \\
\hline 6 & 0.680 & 0.320 & 0.903 & 0.097 & 0.004 & 0.996 & 1.18 & 0.270 \\
\hline 7 & 0.682 & 0.318 & 0.904 & 0.096 & 0.004 & 0.996 & 1.33 & 0.304 \\
\hline 8 & 0.685 & 0.315 & 0.905 & 0.095 & 0.005 & 0.995 & 1.35 & 0.309 \\
\hline 9 & 0.687 & 0.313 & 0.906 & 0.094 & 0.005 & 0.995 & 1.32 & 0.304 \\
\hline 10 & 0.690 & 0.310 & 0.907 & 0.093 & 0.005 & 0.995 & 1.34 & 0.307 \\
\hline 11 & 0.692 & 0.308 & 0.907 & 0.093 & 0.006 & 0.994 & 1.43 & 0.328 \\
\hline 12 & 0.694 & 0.306 & 0.908 & 0.092 & 0.006 & 0.994 & 1.50 & 0.345 \\
\hline 13 & 0.695 & 0.305 & 0.909 & 0.091 & 0.007 & 0.993 & 1.59 & 0.366 \\
\hline 14 & 0.697 & 0.303 & 0.909 & 0.091 & 0.007 & 0.993 & 1.67 & 0.384 \\
\hline 15 & 0.698 & 0.302 & 0.909 & 0.091 & 0.008 & 0.992 & 1.75 & 0.402 \\
\hline
\end{tabular}

Table 7: Elasticities

\begin{tabular}{|c|c|c|c|c|c|c|c|}
\hline \multirow[b]{2}{*}{$\begin{array}{l}\text { type of } \\
\text { elasticities }\end{array}$} & E.1 & E. 2 & E. 3 & E. 4 & E. 5 & E. 6 & \multirow{2}{*}{$\begin{array}{c}\text { E.7 } \\
\text { elasticities of supply } \\
\text { w.r.t. resale value }\end{array}$} \\
\hline & \multicolumn{2}{|c|}{$\begin{array}{l}\text { elasticities of demand } \\
\text { w.r.t. new-copy price }\end{array}$} & \multicolumn{2}{|c|}{$\begin{array}{l}\text { elasticities of demand } \\
\text { w.r.t. used-copy price }\end{array}$} & \multicolumn{2}{|c|}{$\begin{array}{l}\text { elasticities of demand } \\
\text { w.r.t. used-copy inventory }\end{array}$} & \\
\hline $\begin{array}{c}\text { weeks } \\
\text { in release }\end{array}$ & $\begin{array}{c}\text { sales of } \\
\text { new copies }\end{array}$ & $\begin{array}{c}\text { sales of } \\
\text { used copies }\end{array}$ & $\begin{array}{c}\text { sales of } \\
\text { new copies }\end{array}$ & $\begin{array}{c}\text { sales of } \\
\text { used copies }\end{array}$ & $\begin{array}{c}\text { sales of } \\
\text { new copies }\end{array}$ & $\begin{array}{c}\text { sales of } \\
\text { used copies }\end{array}$ & $\begin{array}{c}\text { volume sold } \\
\text { to retailers }\end{array}$ \\
\hline 1 & $\begin{array}{l}-1.98 \\
\end{array}$ & & & & & & \\
\hline 2 & -2.14 & 0.222 & 0.013 & -1.87 & & & 1.42 \\
\hline 3 & -2.18 & 0.169 & 0.044 & -1.82 & -0.019 & 0.782 & 1.31 \\
\hline 4 & -2.22 & 0.131 & 0.070 & -1.77 & -0.018 & 0.513 & 1.22 \\
\hline 5 & -2.23 & 0.115 & 0.079 & -1.73 & -0.010 & 0.260 & 1.16 \\
\hline 6 & -2.23 & 0.112 & 0.080 & -1.70 & -0.006 & 0.188 & 1.10 \\
\hline 7 & -2.24 & 0.105 & 0.081 & -1.65 & -0.004 & 0.150 & 1.03 \\
\hline 8 & -2.24 & 0.103 & 0.081 & -1.62 & -0.004 & 0.128 & 0.986 \\
\hline 9 & -2.24 & 0.103 & 0.080 & -1.59 & -0.003 & 0.099 & 0.951 \\
\hline 10 & -2.25 & 0.101 & 0.079 & -1.56 & -0.003 & 0.085 & 0.894 \\
\hline 11 & -2.25 & 0.098 & 0.078 & -1.50 & -0.002 & 0.072 & 0.838 \\
\hline 12 & -2.25 & 0.096 & 0.077 & -1.47 & -0.002 & 0.058 & 0.807 \\
\hline 13 & -2.25 & 0.093 & 0.076 & -1.41 & -0.001 & 0.051 & 0.760 \\
\hline 14 & -2.26 & 0.091 & 0.075 & -1.37 & -0.001 & 0.047 & 0.728 \\
\hline 15 & -2.26 & 0.088 & 0.074 & -1.34 & -0.002 & 0.060 & 0.694 \\
\hline Average & -2.21 & 0.116 & 0.071 & -1.60 & -0.006 & 0.192 & 0.993 \\
\hline
\end{tabular}


Table 8: Proportion of Switchers to New Copies due to a 1\% Increase in Used-Copy Price

\begin{tabular}{cccc}
$\begin{array}{c}\text { weeks } \\
\text { in release }\end{array}$ & aggregate & type 1 & type 2 \\
\hline \hline 1 & & & \\
2 & 0.118 & 0.117 & 0.135 \\
3 & 0.080 & 0.076 & 0.114 \\
4 & 0.062 & 0.058 & 0.101 \\
5 & 0.056 & 0.052 & 0.096 \\
6 & 0.053 & 0.049 & 0.093 \\
7 & 0.049 & 0.045 & 0.089 \\
8 & 0.049 & 0.045 & 0.090 \\
9 & 0.050 & 0.045 & 0.090 \\
10 & 0.050 & 0.046 & 0.090 \\
11 & 0.047 & 0.043 & 0.088 \\
12 & 0.046 & 0.042 & 0.086 \\
13 & 0.044 & 0.040 & 0.083 \\
14 & 0.042 & 0.039 & 0.081 \\
15 & 0.041 & 0.038 & 0.080 \\
\hline Average & 0.056 & 0.052 & 0.094 \\
\hline
\end{tabular}

Table 9: Percentage change in profits due to elimination of used game market

\begin{tabular}{|c|c|c|c|c|}
\hline & Average & S.D. & Min & Max \\
\hline \multicolumn{5}{|l|}{ Under observed flat-prices } \\
\hline$\%$ change in publisher's profits & $-10.30 \%$ & $4.41 \%$ & $-19.7 \%$ & $1.71 \%$ \\
\hline \multicolumn{5}{|l|}{ Under optimal flat-prices } \\
\hline$\%$ change in new-copy price (from observed price) & $-32.7 \%$ & $6.63 \%$ & $-39.0 \%$ & $-6.30 \%$ \\
\hline$\%$ change in publisher's profits & $18.6 \%$ & $6.14 \%$ & $1.31 \%$ & $31.6 \%$ \\
\hline
\end{tabular}


Figure 1: Average quantities demanded for new video games

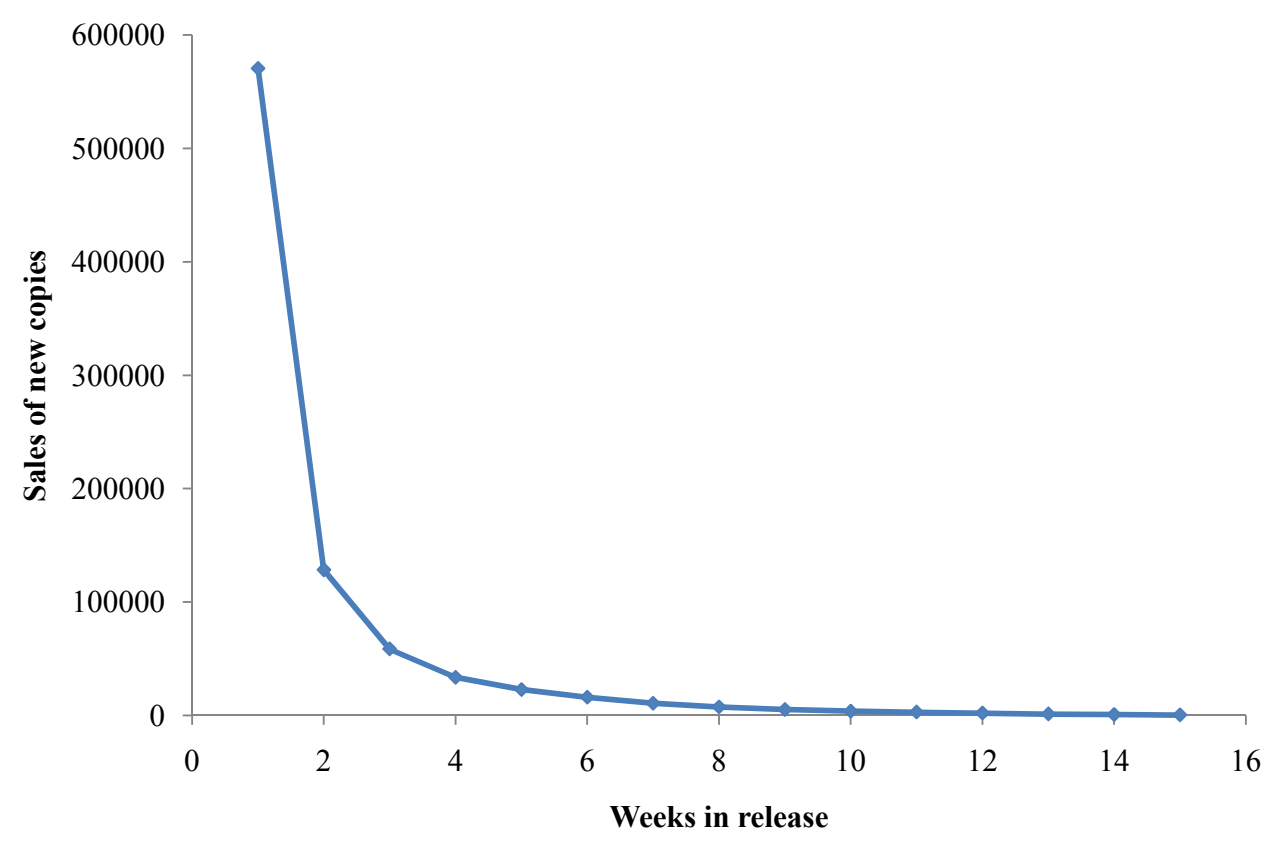

Figure 2: Average quantities demanded and supplied and inventory level for used video games

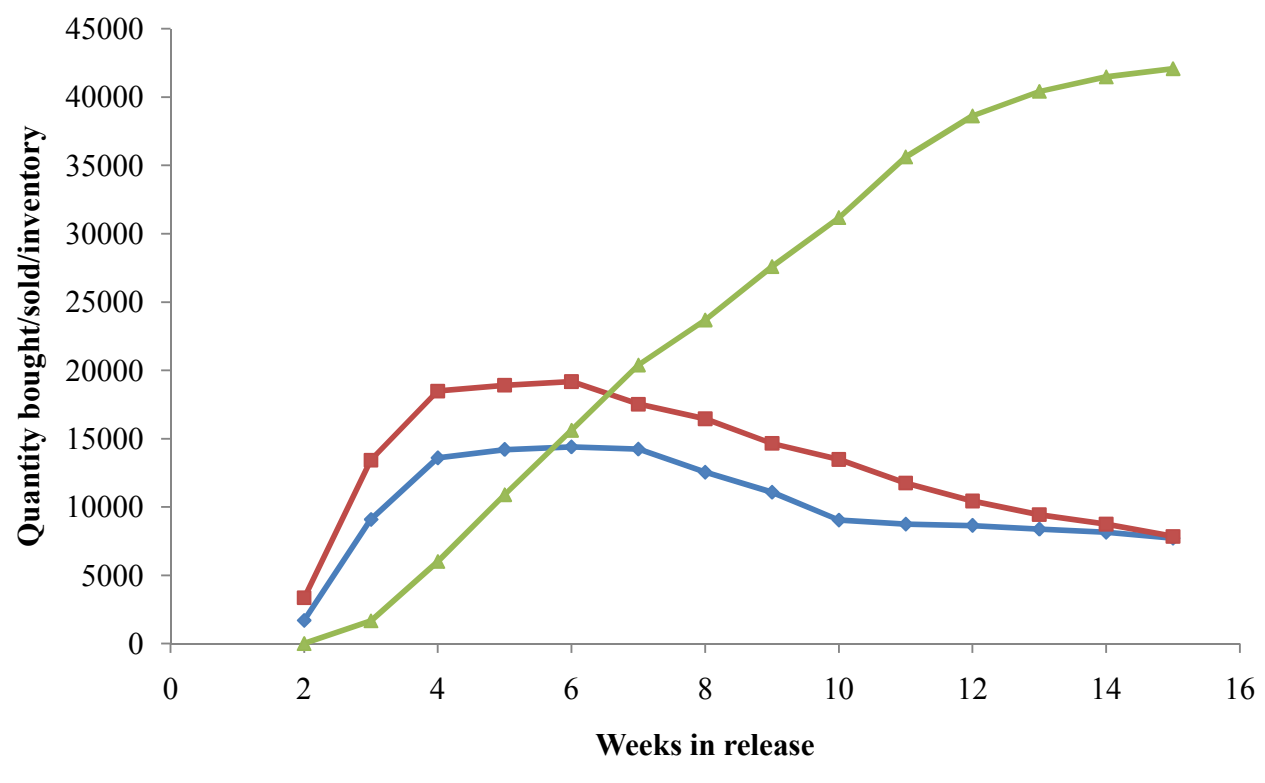

$\multimap$ quantity bought by consumers $\rightarrow$ quantity sold by consumers $\rightarrow$ inventory 
Figure 3: Average price and resale value of used video games

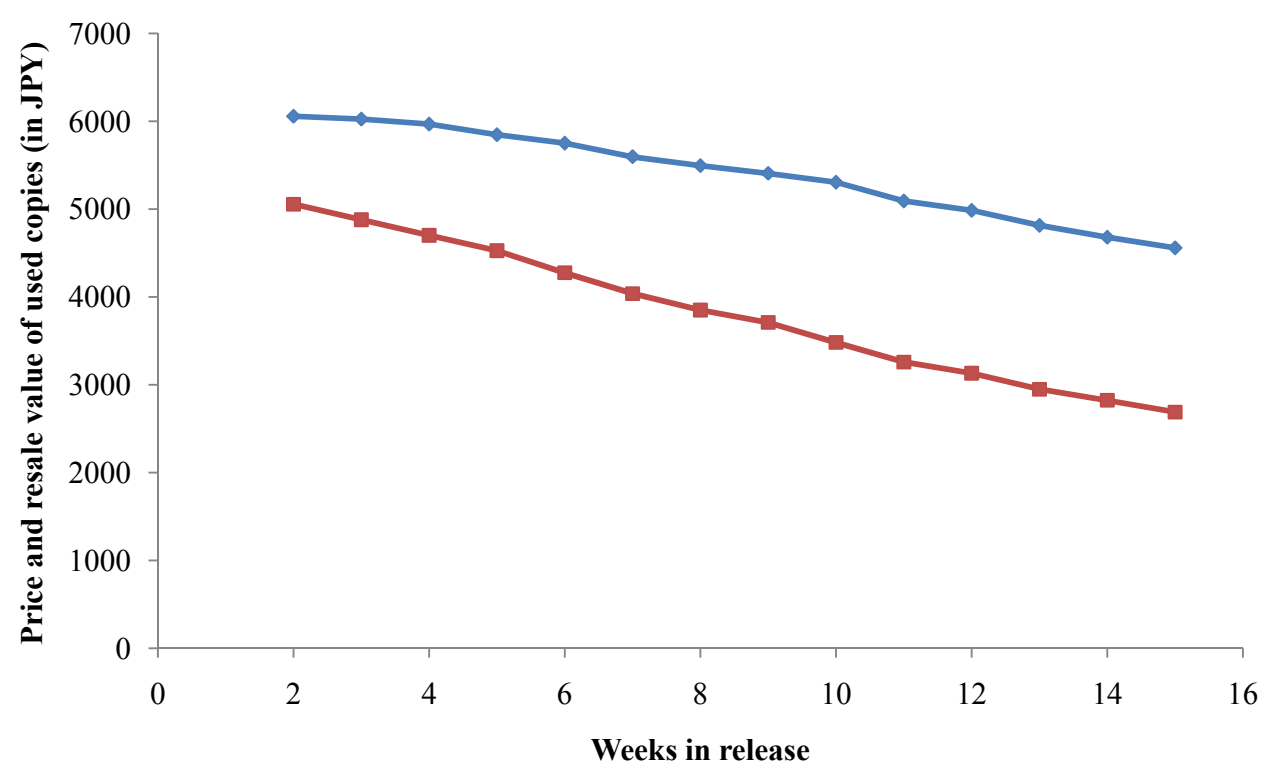

$\multimap$ price $\rightarrow$ resale value

Figure 4: Observed versus Predicted Sales of New Copies

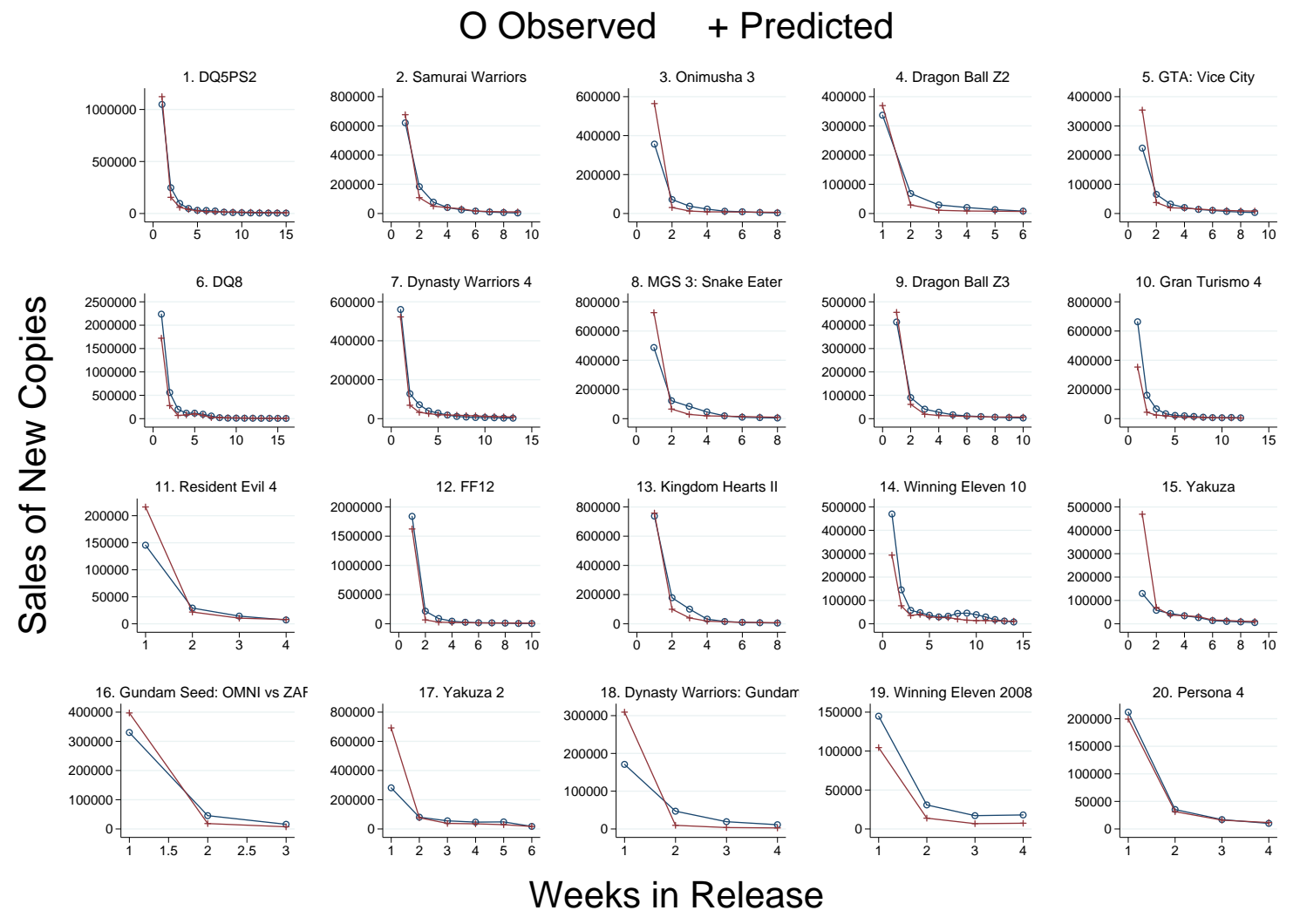


Figure 5: Observed versus Predicted Sales of Used Copies

\section{O Observed + Predicted}
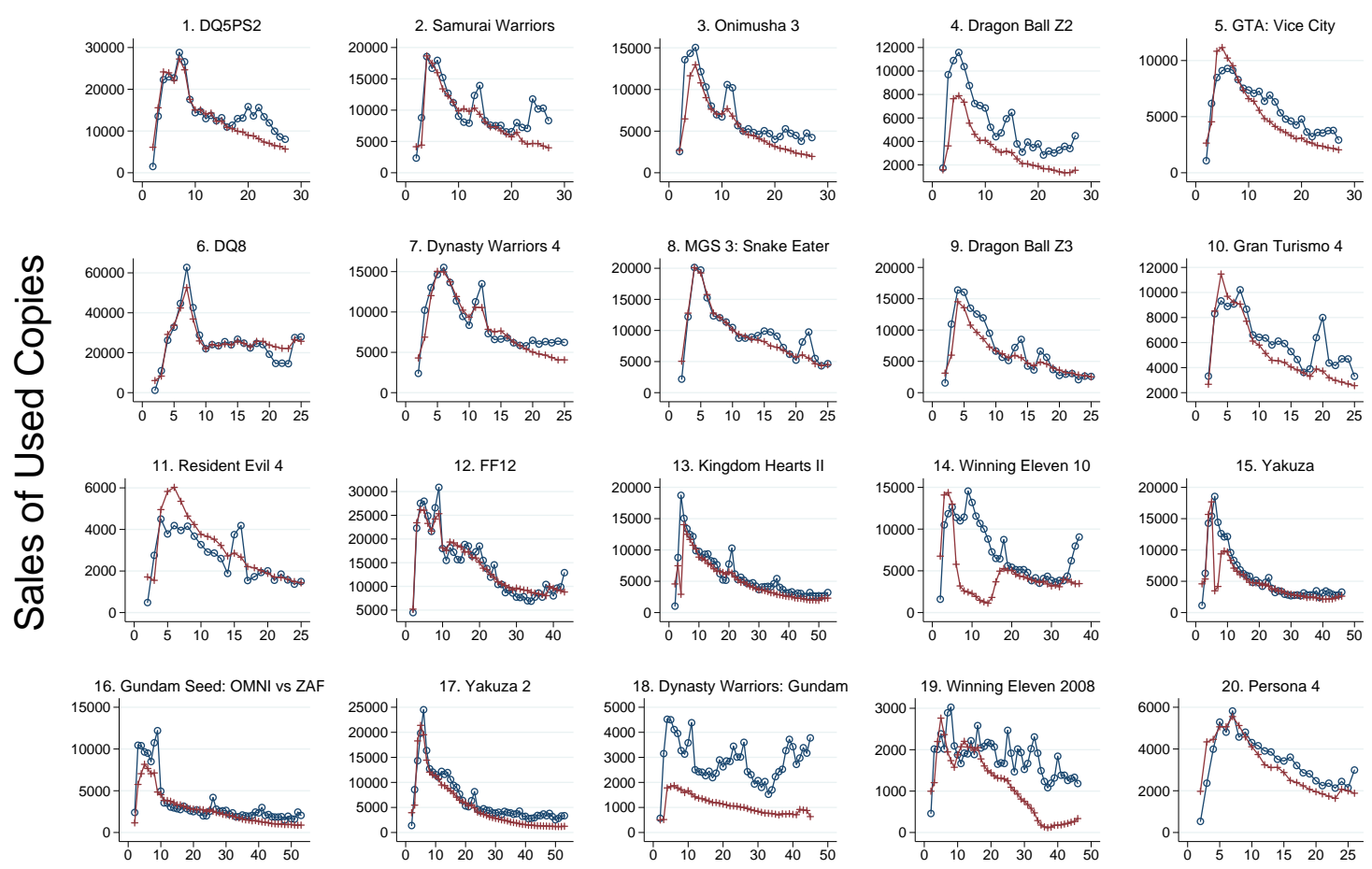

Weeks in Release

Figure 6: Observed versus Predicted Volume Sold to Retailers by Consumers

\section{O Observed + Predicted}
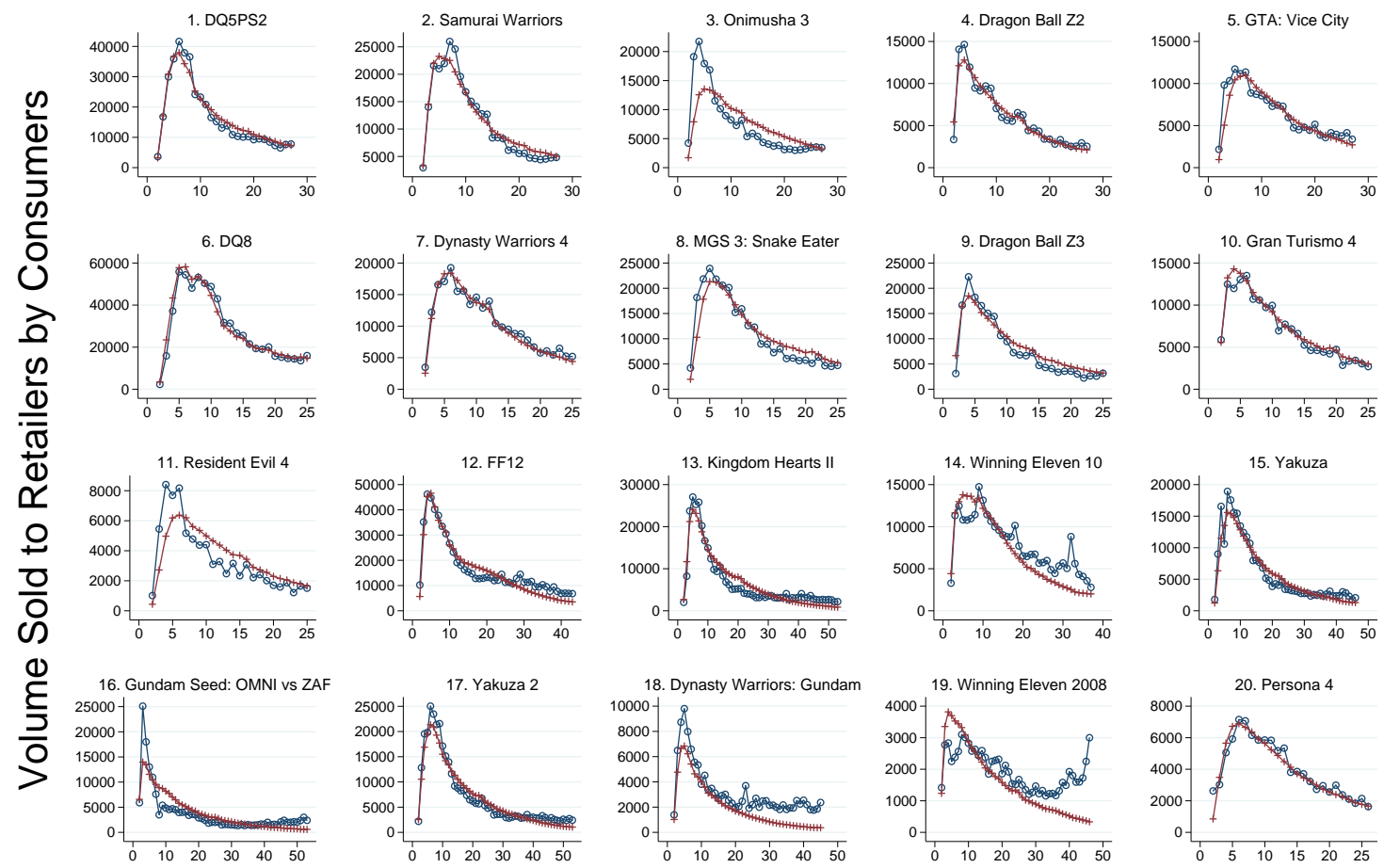

Weeks in Release 
Figure 7: Observed versus Predicted Prices of Used Copies
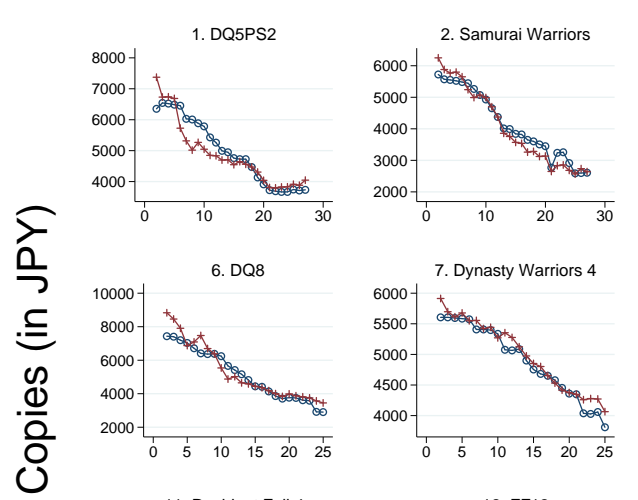

O Observed + Predicted
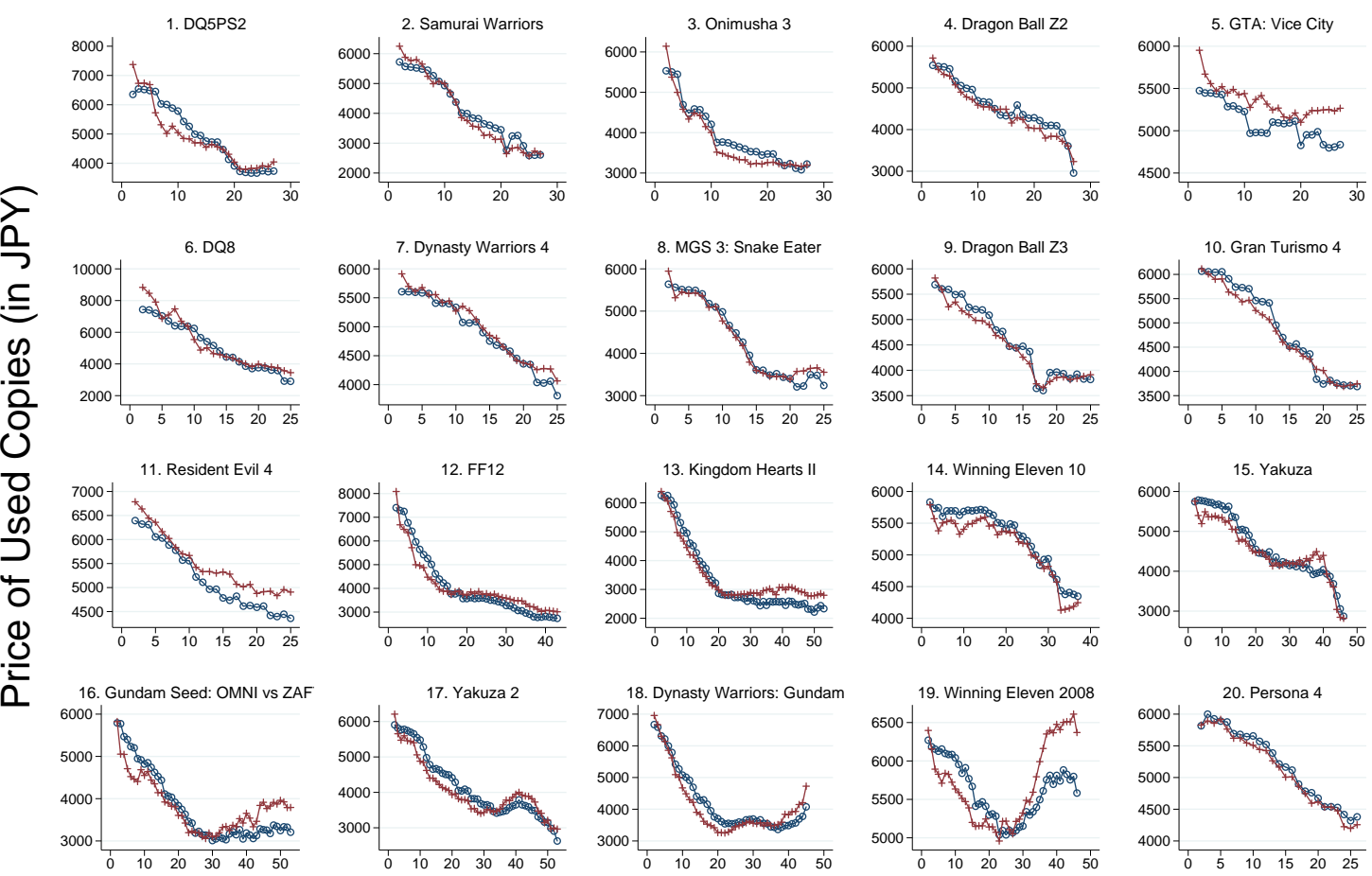

Weeks in Release

Figure 8: Observed versus Predicted Resale Value of Used Copies

O Observed + Predicted
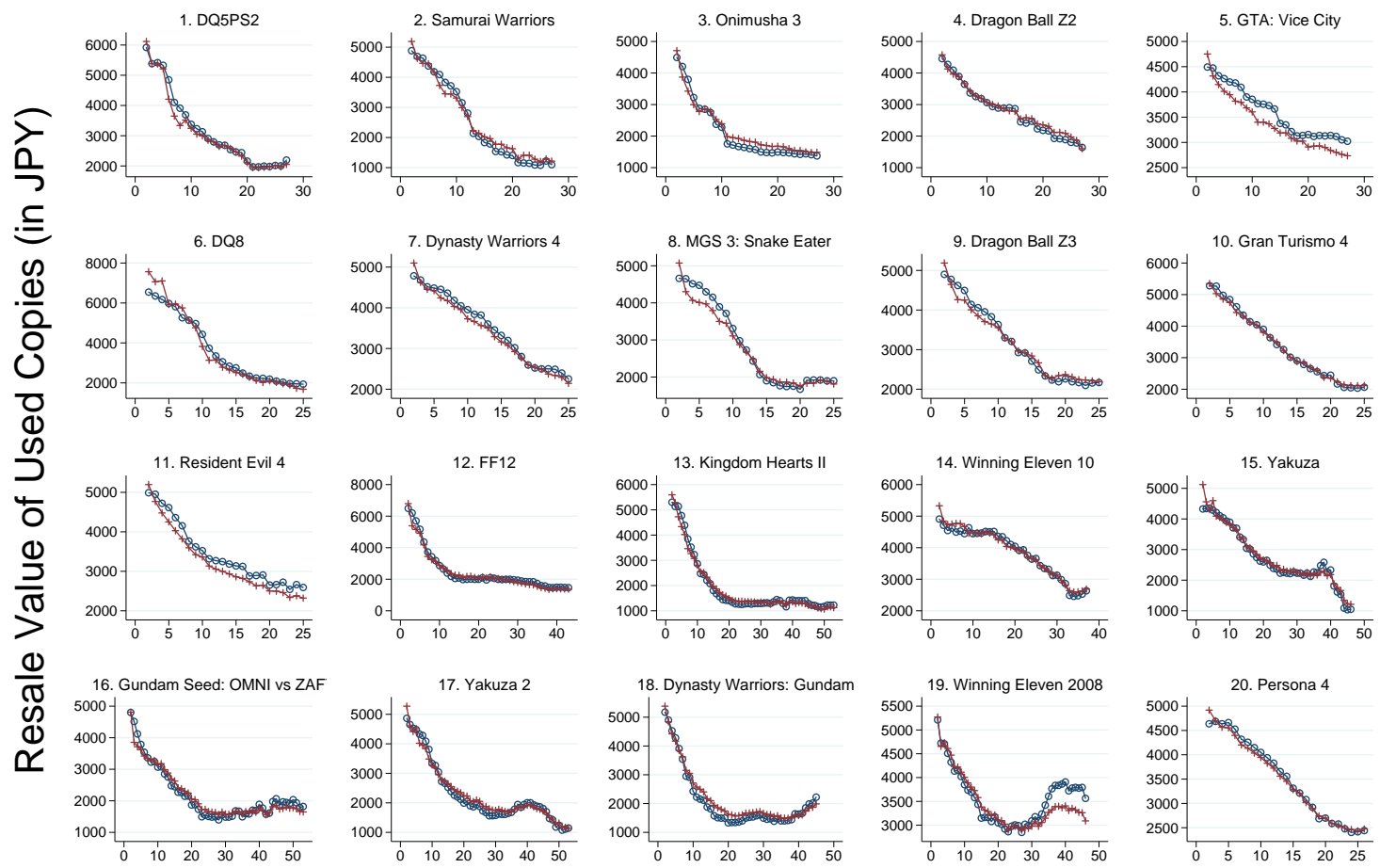

Weeks in Release 
Figure 9: Average percentage change in sales of new copies due to elimination of used game market

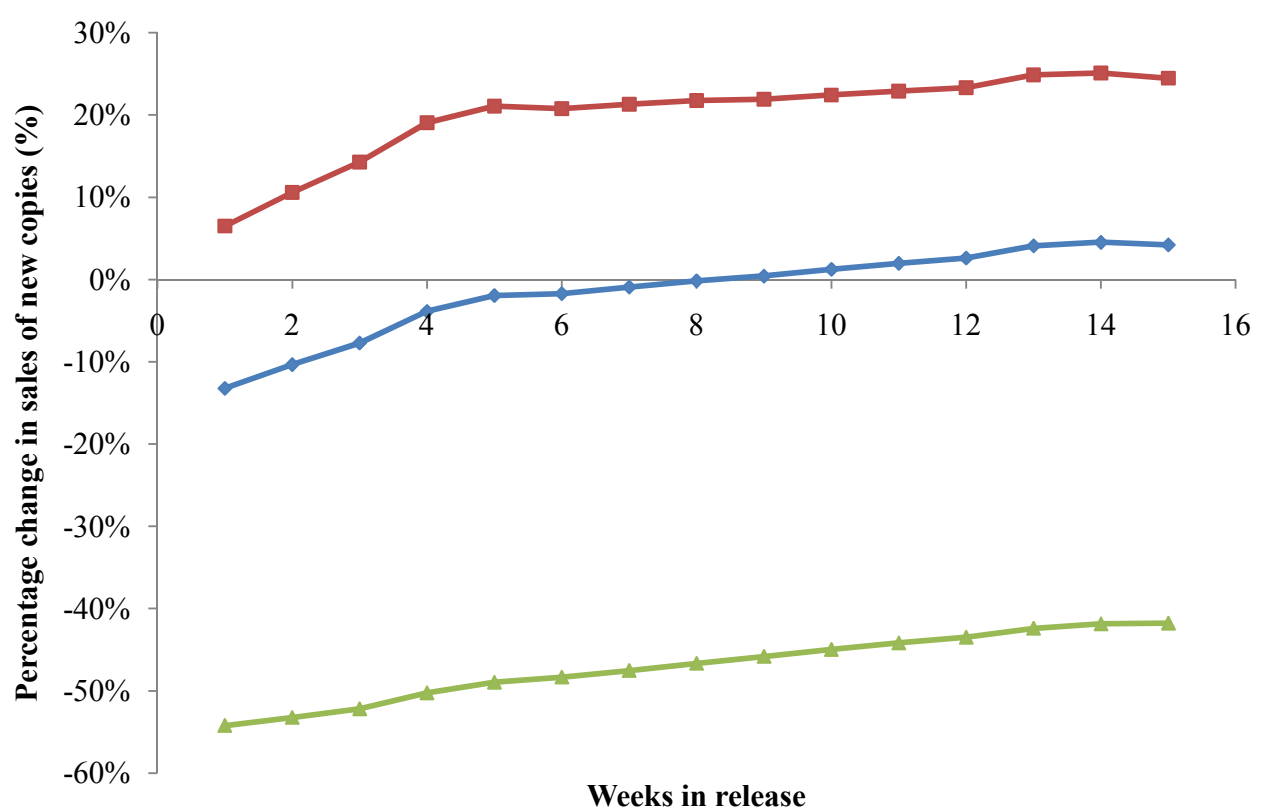

$\multimap$ aggregate $\rightarrow$ type $1 \multimap$ type 2

Figure 10: Average value of having the future selling opportunity

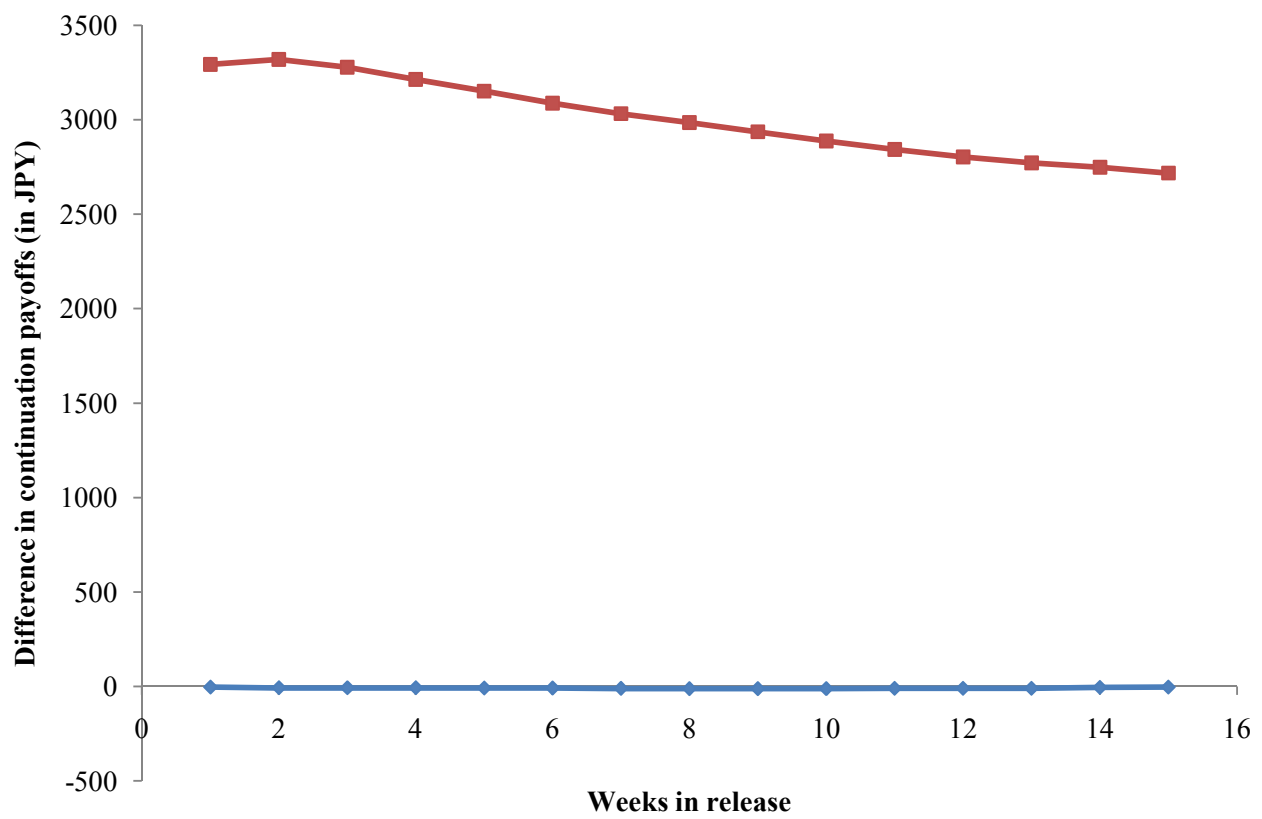

$\longrightarrow$ type $1 \longrightarrow$ type 2 


\section{A Appendix}

\section{A.1 The procedure for the estimation algorithm}

This appendix discusses the details for the estimation algorithm described in section 5. For more details about the general algorithm, see Ishihara and Ching (2012).

In the following exposition, we drop the subscript for type $(l)$ and the superscript for game $(g)$. Let $\theta_{d}$ and $\theta_{s}$ be the vectors of demand-side parameters and pseudo-policy function parameters, respectively. In the context of the present model, the output of the algorithm in outer-loop iteration $m$ is,

$$
H^{m}=\left\{\theta_{d}^{n}, \theta_{s}^{n}, \theta_{d}^{* n},\left\{\tilde{V}^{n}\left(b_{t}^{n} ; \theta_{d}^{* n}\right)\right\}_{t=2}^{T},\left\{\tilde{W}^{n}\left(s_{t, \tau}^{n} ; \theta_{d}^{* n}\right) \forall \tau\right\}_{t=2}^{T}\right\}_{n=m-N}^{m-1},
$$

where $\tilde{V}^{n}$ and $\tilde{W}^{n}$ are consumer's pseudo-value functions for buying and selling decisions in iteration $n$, respectively; $b_{t}^{n}=\left(p_{1}, \tilde{p}_{2 t}^{n}, \tilde{r}_{t}^{n}, \tilde{Y}_{t}^{n}, \tilde{C}_{t}^{n}, \tilde{\xi}_{d}^{n}, t\right)$ and $s_{t, \tau}^{n}=\left(\tilde{r}_{t}^{n}, \tilde{Y}_{t}^{n}, \tilde{\xi}_{s}^{n}, t, \tau\right)$ are vectors of state variables for buying and selling decisions in iteration $n$, respectively; $N$ is the number of past pseudo-value functions used for approximating the expected value functions; $\theta_{d}^{n}$ and $\theta_{s}^{n}$ are the accepted parameter vectors of the demand-side model and the pseudo-policy functions in iteration $n$, respectively; $\theta_{d}^{* n}$ is the candidate parameter vector for the demand-side model in iteration $n ;\left(\tilde{p}_{2 t}^{n}, \tilde{r}_{t}^{n}, \tilde{Y}_{t}^{n}, \tilde{C}_{t}^{n}\right)$ is a vector of random draw from a uniform distribution with the range defined by the lower- and upper-bound of their observed values; $\left(\tilde{\xi}_{d}^{n}, \tilde{\xi}_{s}^{n}\right)$ are drawn from the normal distributions specified in the model.

\section{A.1.1 Pseudo-value function setup}

A consumer's pseudo-value functions for selling decision at time $t$ with duration of ownership $\tau$ in iteration $m$ are defined as follows:

$$
\begin{aligned}
\tilde{W}^{m}\left(s_{t, \tau}^{m} ; \theta_{d}^{* m}\right) & =E_{e} \max _{k \in\{0,1\}}\left\{\tilde{W}_{k}^{m}\left(s_{t, \tau}^{m} ; \theta_{d}^{* m}\right)+e_{i k t}\right\} \\
& =\ln \left\{\sum_{k \in\{0,1\}} \exp \left(\tilde{W}_{k}^{m}\left(s_{t, \tau}^{m} ; \theta_{d}^{* m}\right)\right)\right\}
\end{aligned}
$$


where the second equality follows from the assumption that $e_{i k t}$ is type 1 extreme value distributed; $\tilde{W}_{k}^{m}$ 's are consumer's pseudo alternative-specific value functions in iteration $m$, which are given by

$$
\tilde{W}_{k}^{m}\left(s_{t, \tau}^{m} ; \theta_{d}^{* m}\right)= \begin{cases}\alpha \tilde{r}_{t}^{m}-\mu_{i}+\tilde{\xi}_{s}^{m} & \text { selling, } \\ v(t, \tau)+\beta \hat{E}^{m}\left[W\left(s_{t+1, \tau+1} ; \theta_{d}^{* m}\right) \mid s_{t, \tau}^{m}\right] & \text { keeping. }\end{cases}
$$

The pseudo-expected value function for selling decision, $\hat{E}^{m}\left[W_{l}\left(. ; \theta_{d}^{* m}\right) \mid.\right]$, is defined as the weighted average of the past pseudo-value functions for selling decision in period $t+1$ :

$$
\begin{aligned}
\hat{E}^{m} & {\left[W\left(s_{t+1, \tau+1} ; \theta_{d}^{* m}\right) \mid s_{t, \tau}^{m}\right] } \\
& =\sum_{n=m-N}^{m-1} \tilde{W}^{s}\left(s_{t+1, \tau+1}^{n} ; \theta_{d}^{* n}\right) \frac{K_{h}\left(\theta_{d}^{* m}-\theta_{d}^{* n}\right) f_{s}\left(\tilde{r}_{t+1}^{n}, \tilde{Y}_{t+1}^{n} \mid s_{t, \tau}^{m}\right)}{\sum_{q=m-N}^{m-1} K_{h}\left(\theta_{d}^{* m}-\theta_{d}^{* q}\right) f_{s}\left(\tilde{r}_{t+1}^{q}, \tilde{Y}_{t+1}^{q} \mid s_{t, \tau}^{m}\right)},
\end{aligned}
$$

where $K_{h}($.$) is a Gaussian kernel with bandwidth h$, and $f_{s}(. \mid$.$) is the transition density recovered in the$ first-stage estimation. The relevant state variables for the transition density are $(r, Y)$. Other variables in $s_{t, \tau}$ are either i.i.d. $\left(\xi_{s}\right)$ or deterministic $(t, \tau)$. Note that the kernel captures the idea that one assigns higher weights to the past pseudo-value functions which are evaluated at parameter vectors that are closer to $\theta_{d}^{* m}$. Also, we integrate $r_{t+1}$ and $Y_{t+1}$ out by the weighted average, where weights are given by the transition probabilities. In contrast, we do not need to weigh $\xi_{s t+1}$ because they are drawn from the distribution specified in the model.

Consumers' pseudo-value functions for buying decision at time $t$ in iteration $m$ are defined as follows:

$$
\begin{aligned}
\tilde{V}^{m}\left(b_{t}^{m} ; \theta_{d}^{* m}\right) & =E_{\epsilon} \max _{j \in\{0,1,2\}}\left\{\tilde{V}_{j}^{m}\left(b_{t}^{m} ; \theta_{d}^{* m}\right)+\epsilon_{i j t}\right\}, \\
& =\ln \left\{\sum_{j \in\{0,1,2\}} \exp \left(\tilde{V}_{j}^{m}\left(b_{t}^{m} ; \theta_{d}^{* m}\right)\right)\right\}
\end{aligned}
$$

where $\tilde{V}_{j}^{m}$ 's are consumer's pseudo alternative-specific value functions in iteration $m$, which are given by

$$
\begin{aligned}
& \tilde{V}_{j}^{m}\left(b_{t}^{m} ; \theta_{d}^{* m}\right) \\
& \quad= \begin{cases}v(t, 0)-\alpha p_{1}+\tilde{\xi}_{1}^{m}+\beta \hat{E}^{m}\left[W\left(s_{t+1, \tau=1} ; \theta_{d}^{* m}\right) \mid s_{t, \tau=0}^{m}\right] & \text { new copy, } \\
v(t, 0)-\alpha \tilde{p}_{2 t}^{m}+\tilde{\xi}_{2}^{m}-l_{Y}\left(\tilde{Y}_{t}^{m} ; \lambda_{i}\right)+\beta \hat{E}^{m}\left[W\left(s_{t+1, \tau=1} ; \theta_{d}^{* m}\right) \mid s_{t, \tau=0}^{m}\right] & \text { used copy, } \\
l_{C}\left(\tilde{C}_{t}^{m} ; \pi\right)+\beta \hat{E}^{m}\left[V\left(b_{t+1} ; \theta_{d}^{* m}\right) \mid b_{t}^{m}\right] & \text { no purchase. }\end{cases}
\end{aligned}
$$

The pseudo-expected future value function for buying decision, $\hat{E}^{m}\left[V\left(, ; \theta_{d}^{* m}\right) \mid.\right]$, is defined as the weighted 
average of the past pseudo-value functions for buying decision in period $t+1$ :

$$
\hat{E}^{m}\left[V\left(b_{t+1} ; \theta_{d}^{* m}\right) \mid b_{t}^{m}\right]=\sum_{n=m-N}^{m-1} \tilde{V}\left(b_{t+1}^{n} ; \theta_{d}^{* n}\right) \frac{K_{h}\left(\theta_{d}^{* m}-\theta_{d}^{* n}\right) f_{b}\left(\tilde{p}_{2 t+1}^{n}, \tilde{r}_{t+1}^{n}, \tilde{Y}_{t+1}^{n}, \tilde{C}_{t+1}^{n} \mid b_{t}^{m}\right)}{\sum_{q=m-N}^{m-1} K_{h}\left(\theta_{d}^{* m}-\theta_{d}^{* q}\right) f_{b}\left(\tilde{p}_{2 t+1}^{q}, \tilde{r}_{t+1}^{q}, \tilde{Y}_{t+1}^{q}, \tilde{C}_{t+1}^{q} \mid b_{t}^{m}\right)}
$$

Note again that this weighted average integrates out $p_{2 t+1}, r_{t+1}, Y_{t+1}, C_{t+1}$, and $\xi_{d t+1}$.

\section{A.1.2 Step-by-step procedure}

Each MCMC iteration in the proposed algorithm consists of five blocks:

1. Draw $\sigma_{\xi}^{m}=\left(\sigma_{\xi_{1}}, \sigma_{\xi_{2}}, \sigma_{\xi_{s}}\right)$ directly from their posterior distributions conditional on $\xi_{t}^{g, m-1}=\left(\xi_{1 t}^{g, m-1}, \xi_{2 t}^{g, m-1}, \xi_{s t}^{g, m-1}\right)$ for all observed $t$ and $g$.

2. Draw $\xi_{t}^{g, m}$ for all observed $t$ and $g$ conditional on the data, $\sigma_{\xi}^{m}, \theta_{d}^{m-1}$ and $\theta_{s}^{m-1}$ using randomwalk Metropolis-Hastings. In the Metropolis-Hastings algorithm, the joint-likelihood of the quantity demanded, quantity supplied, used price, and resale value will be used to compute the acceptance probability.

3. Draw $\theta_{d}^{m}$ conditional on the data, $\left\{\xi_{t}^{m}\right\}$ and $\theta_{s}^{m-1}$ using the random-walk Metropolis-Hastings algorithm. In the Metropolis-Hastings algorithm, the joint-likelihood of all the observed data will be used. Note that $\theta_{d}^{m}$ affects the likelihood of used price and resale value through the pseudo-policy functions.

4. Draw $\theta_{s}^{m}$ conditional on the data, $\left\{\xi_{t}^{m}\right\}$ and $\theta_{d}^{m}$ using the random-walk Metropolis-Hastings algorithm. In the Metropolis-Hastings algorithm, only the likelihood of the pseudo-policy functions will be used because $\theta_{s}^{m}$ does not enter the demand-side model.

5. Compute the pseudo-value functions for buying and selling decision problems. Starting from the terminal period, we sequentially compute the pseudo-value functions backwards at only one randomly drawn state point in each period. We store them and update $H^{m}$ to $H^{m+1}$.

In deriving the posterior distribution of parameters, we use an inverted gamma prior on $\sigma_{\xi}$, and a flat prior on $\theta_{d}$ and $\theta_{s}$. Also, note that the likelihood used in this algorithm is pseudo-likelihood as it is a 
function of pseudo alternative-specific value functions. Below, we provide a step-by-step procedure for the five blocks described above.

1. Suppose that we are at iteration $m$. We start with

$$
H^{m}=\left\{\theta_{d}^{n}, \theta_{s}^{n}, \theta_{d}^{* n},\left\{\tilde{V}^{n}\left(b_{t}^{n} ; \theta_{d}^{* n}\right)\right\}_{t=2}^{T},\left\{\tilde{W}^{n}\left(s_{t, \tau}^{n} ; \theta_{d}^{* n}\right) \forall \tau\right\}_{t=2}^{T}\right\}_{n=m-N}^{m-1}
$$

where $N$ is the number of past iterations used for expected value function approximations.

2. Block 1: Draw $\sigma_{\xi}^{m}=\left(\sigma_{\xi_{1}}, \sigma_{\xi_{2}}, \sigma_{\xi_{s}}\right)$ directly from their posterior distributions (inverted gamma) conditional on $\xi_{t}^{g, m-1}=\left(\xi_{1 t}^{g, m-1}, \xi_{2 t}^{g, m-1}, \xi_{s t}^{g, m-1}\right)$ for all observed $t$ and $g$.

3. Block 2: For each observed $t$ and $g$, draw $\xi_{t}^{g, m}$ from its posterior distribution conditional on $\sigma_{\xi_{1}}^{m}, \theta_{d}^{m-1}$, $\theta_{s}^{m-1},\left\{\xi_{k}^{g, m}\right\}_{k=1}^{t-1}$, and $\left\{\xi_{k}^{g, m-1}\right\}_{k=t+1}^{T^{g}}$ where $T^{g}$ is the length of sample periods for game $g$. Here, we will draw $\xi_{1 t}^{g, m}, \xi_{2 t}^{g, m}$, and $\xi_{s t}^{g, m}$, separately, and from $t=1$. Below, we will describe how to draw $\xi_{1 t}^{g, m}$, but a similar procedure can be applied for drawing $\xi_{2 t}^{g, m}$ and $\xi_{s t}^{g, m}$ with appropriate modifications.

(a) Draw $\xi_{1 t}^{g, * m}$ (candidate parameter value).

(b) We compute the pseudo-joint likelihood at $\xi_{1 t}^{g, * m}$ conditional on $\left\{\xi_{k}^{g, m}\right\}_{k=1}^{t-1}, \xi_{2 t}^{g, m-1}, \xi_{s t}^{g, m-1},\left\{\xi_{k}^{g, m-1}\right\}_{k=t+1}^{T^{g}}$, $\theta_{d}^{m-1}$ and $\theta_{s}^{m-1}$. Note that conditional on $\sigma_{\xi_{1}}^{m}$, the pseudo-joint likelihood prior to time $t$ does not depend on $\xi_{1 t}^{g, * m}$. But $\xi_{1 t}^{g, * m}$ would affect the potential size of buyers and owners in the future, so the pseudo-joint likelihood after time $t$ would depend on $\xi_{1 t}^{g, * m}$. Thus, we need to compute the pseudo-joint likelihood at time $t$ and later. To compute the pseudojoint likelihood, we need to obtain the pseudo-alternative specific value functions for both buying and selling decisions at the observed state vectors denoted by $\left(\mathrm{b}_{t}, \mathrm{~s}_{t, \tau}\right)$ from time $t$ to $T^{g}$ : $\tilde{V}_{j}^{m}\left(\mathrm{~b}_{t} ; \theta_{d}^{m-1}\right)$ and $\left\{\tilde{W}_{k}^{m}\left(\mathrm{~s}_{t, \tau} ; \theta_{d}^{m-1}\right)\right\}_{\tau=1}^{t-1}$. First, to obtain $\tilde{V}_{j}^{m}\left(\mathrm{~b}_{t} ; \theta_{d}^{m-1}\right)$, we need to calculate both $\hat{E}^{m}\left[V\left(b_{t+1} ; \theta_{d}^{m-1}\right) \mid \mathrm{b}_{t}\right]$ (pseudo-expected value function when consumers choose no purchase option) and $\hat{E}^{m}\left[W\left(s_{t+1, \tau=1} ; \theta_{d}^{m-1}\right) \mid \mathbf{s}_{t, \tau=0}\right]$ (pseudo-expected value function when consumers choose to buy a new or used copy), which are computed as the weighted average of past-pseudo value functions evaluated at time $t+1$ : 
i. For $\hat{E}^{m}\left[V\left(b_{t+1} ; \theta_{d}^{m-1}\right) \mid \mathrm{b}_{t}\right]$, we take the weighted average of $\left\{\tilde{V}^{n}\left(b_{t+1}^{n} ; \theta_{d}^{* n}\right)\right\}_{n=m-N}^{m-1}$ as in Equation $(26)$.

ii. For $\hat{E}^{m}\left[W\left(s_{t+1, \tau=1} ; \theta_{d}^{m-1}\right) \mid \mathbf{s}_{t, \tau=0}\right]$, we take the weighted average of $\left\{\tilde{W}^{n}\left(s_{t+1, \tau=1}^{n} ; \theta_{d}^{* n}\right)\right\}_{n=m-N}^{m-1}$ as in Equation (23). Note that if consumers buy at time $t$, they will have owned the game for one period when they reach $t+1$. Thus, the set of past pseudo-value functions used here only include those evaluated at $\tau=1$.

Next, to obtain $\left\{\tilde{W}_{k}^{m}\left(\mathrm{~s}_{t, \tau} ; \theta_{d}^{m-1}\right)\right\}_{\tau=1}^{t-1}$, we need to calculate $\left\{\hat{E}^{m}\left[W\left(s_{t+1, \tau+1} ; \theta_{d}^{m-1}\right) \mid s_{t, \tau}\right]\right\}_{\tau=1}^{t-1}$ by the weighted average of the past pseudo-value functions $\left\{\tilde{W}^{n}\left(s_{t+1, \tau+1}^{n} ; \theta_{d}^{* n}\right)\right\}_{n=m-N}^{m-1}$ as in Equation (23).

(c) Similarly, we compute the pseudo-joint likelihood at $\xi_{1 t}^{g, m-1}$ conditional on $\left\{\xi_{k}^{g, m}\right\}_{k=1}^{t-1}, \xi_{2 t}^{g, m-1}$, $\xi_{s t}^{g, m-1},\left\{\xi_{k}^{g, m-1}\right\}_{k=t+1}^{T^{g}}, \theta_{d}^{m-1}$ and $\theta_{s}^{m-1}$.

(d) Based on the pseudo-joint likelihoods at $\xi_{1 t}^{g, * m}$ and $\xi_{2 t}^{g, m-1}$, we compute the acceptance probability for $\xi_{1 t}^{g, * m}$ and decide whether to accept (i.e., set $\xi_{1 t}^{g, m}=\xi_{1 t}^{g, * m}$ ) or reject (i.e., set $\xi_{1 t}^{g, m}=\xi_{1 t}^{g, m-1}$ ).

Using a similar procedure, draw $\xi_{2 t}^{g, m}$ and $\xi_{s t}^{g, m}$. Note that drawing $\xi_{s t}^{g, m}$ does not require us to compute $\tilde{V}_{j}^{m}$ because conditional on $\sigma_{\xi_{s}}^{m}, \xi_{s t}^{g, * m}$ does not influence the likelihood function for buying decisions.

4. Block 3: Use the Metropolis-Hastings algorithm to draw $\theta_{d}^{m}$ conditional on $\left\{\xi_{t}^{m}\right\}$ and $\theta_{s}^{m-1}$.

(a) Draw $\theta_{d}^{* m}$ (candidate parameter vector).

(b) We compute the pseudo-joint likelihood at $\theta_{d}^{* m}$ conditional on $\left\{\xi_{t}^{m}\right\}$ and $\theta_{s}^{m-1}$ based on the pseudoalternative specific value functions for both buying and selling decisions at $\theta_{d}^{* m}: \tilde{V}_{j}^{m}\left(\mathrm{~b}_{t} ; \theta_{d}^{* m}\right)$ and $\left\{\tilde{W}_{k}^{m}\left(\mathrm{~s}_{t, \tau} ; \theta_{d}^{* m}\right)\right\}_{\tau=1}^{t-1}$ for all observed $t$ and $g$. To obtain $\tilde{V}_{j}^{m}\left(\mathrm{~b}_{t} ; \theta_{d}^{* m}\right)$, we need to calculate both $\hat{E}^{m}\left[V\left(b_{t+1} ; \theta_{d}^{* m}\right) \mid \mathbf{b}_{t}\right]$ and $\hat{E}^{m}\left[W\left(s_{t+1, \tau=1} ; \theta_{d}^{* m}\right) \mid \mathbf{s}_{t, \tau=0}\right]$, which are computed as the weighted average of past-pseudo value functions evaluated at time $t+1$ :

i. For $\hat{E}^{m}\left[V\left(b_{t+1} ; \theta_{d}^{* m}\right) \mid \mathrm{b}_{t}\right]$, we take the weighted average of $\left\{\tilde{V}^{n}\left(b_{t+1}^{n} ; \theta_{d}^{* n}\right)\right\}_{n=m-N}^{m-1}$ as in Equation $(26)$. 
ii. For $\hat{E}^{m}\left[W\left(s_{t+1, \tau=1} ; \theta_{d}^{* m}\right) \mid \mathbf{s}_{t, \tau=0}\right]$, we take the weighted average of $\left\{\tilde{W}^{n}\left(s_{t+1, \tau=1}^{n} ; \theta_{d}^{* n}\right)\right\}_{n=m-N}^{m-1}$ as in Equation (23). Again, note that if consumers buy at $t$, they will have owned the game for one period when they reach $t+1$. Thus, the set of past pseudo-value functions used here are all evaluated at $\tau=1$.

To obtain $\left\{\tilde{W}_{k}^{m}\left(\mathrm{~s}_{t, \tau} ; \theta_{d}^{* m}\right)\right\}_{\tau=1}^{t-1}$, we only need to calculate $\left\{\hat{E}^{m}\left[W\left(s_{t+1, \tau+1} ; \theta_{d}^{* m}\right) \mid \mathrm{s}_{t, \tau}\right]\right\}_{\tau=1}^{t-1}$ by the weighted average of the past pseudo-value functions $\left\{\tilde{W}^{n}\left(s_{t+1, \tau+1}^{n} ; \theta_{d}^{* n}\right)\right\}_{n=m-N}^{m-1}$ as in Equation (23).

(c) Similarly, we compute the pseudo-joint likelihood at $\theta_{d}^{m-1}$ conditional on $\left\{\xi_{t}^{m}\right\}$ and $\theta_{s}^{m-1}$.

(d) Based on the pseudo-joint likelihoods at $\theta_{d}^{* m}$ and $\theta_{d}^{m-1}$, we compute the acceptance probability for $\theta_{d}^{* m}$ and decide whether to accept (i.e., set $\theta_{d}^{m}=\theta_{d}^{* m}$ ) or reject (i.e., set $\theta_{d}^{m}=\theta_{d}^{m-1}$ ).

5. Block 4: Use the Metropolis-Hastings algorithm to draw $\theta_{s}^{m}$ conditional on $\left\{\xi_{t}^{m}\right\}$ and $\theta_{d}^{m}$.

(a) Draw $\theta_{s}^{* m}$ (candidate parameter vector).

(b) We compute the pseudo-likelihood for pseudo-policy functions at $\theta_{s}^{* m}$ conditional on $\left\{\xi_{t}^{m}\right\}$ and $\theta_{d}^{m}$. Note that the pseudo-alternative specific value functions do not depend on $\theta_{s}^{* m}$, but are required to compute the pseudo-likelihood at $\theta_{s}^{* m}$ since they influence the evolution of equilibrium state variables, which enter pseudo-policy functions. However, they have already been computed in step 4(b) (if $\theta_{d}^{* m}$ has been accepted) or 4(c) (if $\theta_{d}^{* m}$ has been rejected).

(c) To form the acceptance probability of $\theta_{s}^{* m}$, we need the pseudo-likelihood for pseudo-policy functions at $\theta_{s}^{m-1}$ conditional on $\left\{\xi_{t}^{m}\right\}$ and $\theta_{d}^{m}$ as well. Note that this value has been computed in step 4 and needs not be re-computed here.

(d) Based on the pseudo-likelihood for pseudo-policy functions at $\theta_{s}^{* m}$ and $\theta_{s}^{m-1}$, we compute the acceptance probability for $\theta_{s}^{* m}$ and decide whether to accept (i.e., set $\theta_{s}^{m}=\theta_{s}^{* m}$ ) or reject (i.e., set $\left.\theta_{s}^{m}=\theta_{s}^{m-1}\right)$.

6. Block 5: Compute the pseudo-value functions for buying and selling decision problems. 
(a) For each $t=2, \ldots, T$, make a draw of used-copy price $\left(\tilde{p}_{2 t}^{m}\right)$, resale value $\left(\tilde{r}_{t}^{m}\right)$, inventory level $\left(\tilde{Y}_{t}^{m}\right)$, and cumulative number of newly introduced games $\left(\tilde{C}_{t}^{m}\right)$ from uniform distributions with appropriate upper- and lower-bound (e.g., upper- and lower-bound of observed values).

(b) Make a draw of $\tilde{\xi}_{1}^{m}, \tilde{\xi}_{2}^{m}$, and $\tilde{\xi}_{s}^{m}$ from the corresponding distribution based on $\sigma_{\xi_{1}}^{m}, \sigma_{\xi_{2}}^{m}$, and $\sigma_{\xi_{s}}^{m}$.

(c) Start from the terminal period $T$.

i. Compute the value functions $\tilde{V}^{m}\left(b_{T}^{m} ; \theta_{d}^{* m}\right)$ and $\left\{\tilde{W}^{m}\left(s_{T, \tau}^{m} ; \theta_{d}^{* m}\right)\right\}_{\tau=1}^{T-1}$. Note that at time $T$, there is no need to compute the pseudo-expected value function. Thus, the value functions computed at time $T$ are not pseudo-value functions.

ii. Store $\tilde{V}^{m}\left(b_{T}^{m} ; \theta_{d}^{* m}\right)$ and $\left\{\tilde{W}^{m}\left(s_{T, \tau}^{m} ; \theta_{d}^{* m}\right)\right\}_{\tau=1}^{T-1}$.

(d) For $t=T-1, \ldots, 2$, compute the pseudo-value function $\tilde{V}^{m}\left(b_{t}^{m} ; \theta_{d}^{* m}\right)$ and $\left\{\tilde{W}^{m}\left(s_{t, \tau}^{m} ; \theta_{d}^{* m}\right)\right\}_{\tau=1}^{t-1}$.

i. To compute $\tilde{V}^{m}\left(b_{t}^{m} ; \theta_{d}^{* m}\right)$, we need to calculate $\hat{E}^{m}\left[V\left(b_{t+1} ; \theta_{d}^{* m}\right) \mid b_{t}^{m}\right]$ and $\hat{E}^{m}\left[W\left(s_{t+1, \tau=1} ; \theta_{d}^{* m}\right) \mid s_{t, \tau=0}^{m}\right]$ based on Equations (26) and (23), respectively.

ii. To compute $\left\{\tilde{W}^{m}\left(s_{t, \tau}^{m} ; \theta_{d}^{* m}\right)\right\}_{\tau=1}^{t-1}$, we need to calculate $\left\{\hat{E}^{m}\left[W\left(s_{t+1, \tau+1} ; \theta_{d}^{* m}\right) \mid s_{t, \tau}^{m}\right]\right\}_{\tau=1}^{t-1}$ based on Equation (23).

iii. Store $\tilde{V}^{m}\left(b_{t}^{m} ; \theta_{d}^{* m}\right)$ and $\left\{\tilde{W}^{m}\left(s_{t, \tau}^{m} ; \theta_{d}^{* m}\right)\right\}_{\tau=1}^{t-1}$.

7. Go to iteration $m+1$.

In our application in Section 6, we set $N=100$ (\# past pseudo-value functions used for the approximation of expected value functions) and $h=0.01$ (kernel bandwidth).

\section{A.2 The likelihood function}

Assuming that the prediction errors, $\nu_{p t}$ and $\nu_{r t}$, in Equations (19) and (20) are normally distributed, we obtain the conditional likelihood of observing $\left(p_{2 t}^{g}, r_{t}^{g}\right)$,

$$
f_{s}\left(p_{2 t}^{g}, r_{t}^{g} \mid M_{t}^{d, g}, v^{g}(t, 0),\left\{M_{i t}^{s, g}(\tau), v^{g}(t, \tau)\right\}_{\tau=1}^{t-1}, \xi_{1 t}^{g}, \xi_{2 t}^{g}, \xi_{s t}^{g}, Y_{t}^{g}, C_{t}^{g} ; \theta_{s}\right)
$$

where $\theta_{s}$ is the parameter vector of pseudo-policy functions. Note that (i) $v^{g}(t, \tau)$ depends on product characteristics, $X_{g}$; (ii) $M_{t}^{d, g}$ (size of potential buyers) and $M_{t}^{s, g}(\tau)$ (size of owners) are a function of $X_{g}$, 
$p_{1}^{g},\left\{p_{2 m}^{g}, r_{m}^{g}, Y_{m}^{g}\right\}_{m=2}^{t-1},\left\{C_{m}^{g}\right\}_{m=1}^{t-1},\left\{\xi_{1 m}^{g}\right\}_{m=1}^{t-1},\left\{\xi_{2 m}^{g}, \xi_{s m}^{g}\right\}_{m=2}^{t-1}, M_{1}^{d, g}$ (initial size of potential buyers), and $\left\{N_{m}^{g}\right\}_{m=2}^{t}$ (potential buyers who entered at time $m$ ). Thus, we can rewrite $f_{s}$ as

$$
f_{s}\left(p_{2 t}^{g}, r_{t}^{g} \mid\left\{\xi_{1 m}^{g}\right\}_{m=1}^{t},\left\{\xi_{2 m}^{g}, \xi_{s m}^{g}\right\}_{m=2}^{t}, Y_{t}^{g}, C_{t}^{g}, Z_{t}^{g} ; \theta_{s}\right)
$$

where $Z_{t}^{g}=\left\{X_{g}, p_{1}^{g},\left\{p_{2 m}^{g}, r_{m}^{g}, Y_{m}^{g}\right\}_{m=2}^{t-1},\left\{C_{m}^{g}\right\}_{m=1}^{t-1}, M_{1}^{d, g},\left\{N_{m}^{g}\right\}_{m=2}^{t}\right\}$ is a vector of observed variables.

Assume further that the measurement errors, $\varepsilon_{1 t}, \varepsilon_{2 t}, \varepsilon_{s t}$, in Equations (17) and (18) are normally distributed. Then, the conditional likelihood of observing $\left(Q_{1 t}^{g}, Q_{2 t}^{g}, Q_{s t}^{g}\right)$ is written as

$$
f_{d}\left(Q_{1 t}^{g}, Q_{2 t}^{g}, Q_{s t}^{g} \mid M_{t}^{d, g}, v^{g}(t, 0),\left\{M_{t}^{s, g}(\tau), v^{g}(t, \tau)\right\}_{\tau=1}^{t-1}, \xi_{1 t}^{g}, \xi_{2 t}^{g}, \xi_{s t}^{g}, p_{1}^{g}, p_{2 t}^{g}, r_{t}^{g}, Y_{t}^{g}, C_{t}^{g} ; \theta_{d}\right)
$$

where $\theta_{d}$ is the vector of demand-side parameters. Similar to $f_{s}, f_{d}$ can be rewritten as

$$
f_{d}\left(Q_{1 t}^{g}, Q_{2 t}^{g}, Q_{s t}^{g} \mid\left\{\xi_{1 m}^{g}\right\}_{m=1}^{t},\left\{\xi_{2 m}^{g}, \xi_{s m}^{g}\right\}_{m=2}^{t}, p_{2 t}^{g}, r_{t}^{g}, Y_{t}^{g}, C_{t}^{g}, Z_{t}^{g} ; \theta_{d}\right)
$$

The joint likelihood of observing $\left(Q_{1 t}^{g}, Q_{2 t}^{g}, Q_{s t}^{g}, p_{2 t}^{g}, r_{t}^{g}\right)$ is the product of $f_{s}$ and $f_{d}$ :

$$
\begin{gathered}
l\left(Q_{1 t}^{g}, Q_{2 t}^{g}, Q_{s t}^{g}, p_{2 t}^{g}, r_{t}^{g} \mid\left\{\xi_{1 m}^{g}\right\}_{m=1}^{t},\left\{\xi_{2 m}^{g}, \xi_{s m}^{g}\right\}_{m=2}^{t}, Y_{t}^{g}, C_{t}^{g}, Z_{t}^{g} ; \theta_{d}, \theta_{s}\right)= \\
f_{d}\left(Q_{1 t}^{g}, Q_{2 t}^{g}, Q_{s t}^{g} \mid\left\{\xi_{1 m}^{g}\right\}_{m=1}^{t},\left\{\xi_{2 m}^{g}, \xi_{s m}^{g}\right\}_{m=2}^{t}, p_{2 t}^{g}, r_{t}^{g}, Y_{t}^{g}, C_{t}^{g}, Z_{t}^{g} ; \theta_{d}\right) \times \\
f_{s}\left(p_{2 t}^{g}, r_{t}^{g} \mid\left\{\xi_{1 m}^{g}\right\}_{m=1}^{t},\left\{\xi_{2 m}^{g}, \xi_{s m}^{g}\right\}_{m=2}^{t}, Y_{t}^{g}, C_{t}^{g}, Z_{t}^{g} ; \theta_{s}\right) .
\end{gathered}
$$

The likelihood of observing $\mathbf{D}=\left\{\left\{Q_{1 t}^{g}\right\}_{t=1}^{T^{g}},\left\{Q_{2 t}^{g}, Q_{s t}^{g}, p_{2 t}^{g}, r_{t}^{g}\right\}_{t=2}^{T^{g}}\right\}_{g=1}^{G}$ is

$$
\begin{aligned}
& L\left(\mathbf{D} \mid \xi, C, Y, Z ; \theta_{d}, \theta_{s}\right)= \\
& \quad \prod_{g=1}^{G}\left[f_{d}\left(Q_{11}^{g} \mid \xi_{11}^{g}, C_{1}^{g}, Z_{1}^{g} ; \theta_{d}\right) \prod_{t=2}^{T^{g}} l\left(Q_{1 t}^{g}, Q_{2 t}^{g}, Q_{s t}^{g}, p_{2 t}^{g}, r_{t}^{g} \mid\left\{\xi_{1 m}^{g}\right\}_{m=1}^{t},\left\{\xi_{2 m}^{g}, \xi_{s m}^{g}\right\}_{m=2}^{t}, Y_{t}^{g}, C_{t}^{g}, Z_{t}^{g} ; \theta_{d}, \theta_{s}\right)\right]
\end{aligned}
$$

where $G$ is the total number of games, $T^{g}$ is the length of observations for game $g, Y=\left\{\left\{Y_{t}^{g}\right\}_{t=1}^{T^{g}}\right\}_{g=1}^{G}$, $C=\left\{\left\{C_{t}^{g}\right\}_{t=1}^{T^{g}}\right\}_{g=1}^{G}$, and $Z=\left\{\left\{Z_{t}^{g}\right\}_{t=1}^{T^{g}}\right\}_{g=1}^{G}$.

Note that $\left\{\xi_{1 t}^{g}\right\}_{t=1}^{T^{g}},\left\{\xi_{2 t}^{g}, \xi_{s t}^{g}\right\}_{t=2}^{T^{g}}$ are unobservable to the econometricians. In the proposed Bayesian framework, these variables are augmented from the corresponding distributions to form the likelihood $L(\mathbf{D} \mid \cdot)$. 


\section{A.3 Alternative Specifications of the Model}

As robustness checks, we estimate several alternative specifications of the model. In this section, we briefly discuss the results of six specifications. The estimation results are presented in Tables 10 and 11 . In all specifications, we estimate a full model but only report demand parameter estimates.

The three specifications in Table 10 explore different heterogeneity structures from the baseline model. Specification (i) examines if heterogeneity in price-sensitivity alone could explain the data well. We find that two types of consumers differ in price-sensitivity (5.01e-4 versus $2.14 \mathrm{e}-4)$, and the proportion of type-1 consumers (more price-sensitive consumers) is $97 \%$. However, it turns out that type- 1 consumers hardly buy anything, and all sales of new and used copies and the supply of used copies are simply generated by type- 2 consumers. Therefore, the heterogeneity does not play any real role. A natural question is then whether adding heterogeneity in price-sensitivity to the baseline model could improve the model fit significantly. Specification (ii) examines this. We find that after controlling for the heterogeneity in transaction costs, the heterogeneity in price-sensitivity does not play a significant role: the difference in price-sensitivity between the two types is very small.

Specification (iii) allows the intercept for the satiation-based depreciation rate to be heterogeneous and tests if adding such heterogeneity eliminates the heterogeneity in costs for selling a game. This conjecture is valid if the reason why some consumers do not sell their games is because their have a very low satiationbased depreciation rate, not because they have a high selling cost. Our estimates indicate that heterogeneity in transaction costs remains very strong, and that heterogeneity in satiation-based depreciation is almost negligible.

In Table 11, we run another three specifications that alter some model features other than heterogeneity structures. Specification (iv) allows for a correlation between demand shocks for new and used copies (i.e., $\xi_{1 t}^{g}$ and $\xi_{2 t}^{g}$ ). Since the two demand shocks are essentially for the same video game (but new versus used copies), they could be correlated. However, the results show no significant correlation between the two demand shocks - the point estimate is 0.01 and insignificant. In Specification (v), we investigate another 
potential role of the used-copy inventory. We have argued that an increase in the used-copy inventory could lower the cost for buying a used copy. However, it could also signal that the game is of low quality because a high inventory level means that many owners sold their games to retailers but not many buyers bought used copies. To examine this story, we allow the used-copy inventory to affect the utility for no purchase option. Note that such an effect is identified by the correlation between the relative market share of inside to outside options and the inventory level (recall that the effect on the costs for buying a used copy is identified by the correlation between the relative market share of used to new copies and the inventory level). The result shows that the effect is positive and significant, which is consistent with the signalling story, but the magnitude is very small (0.006).

Finally, Specification (vi) estimates the baseline model by assuming that consumers are myopic $(\beta=0)$. Our estimated discount factor (0.902) indicates that consumers discount the future value significantly more than the case when we assume that the discount factor is calibrated by the weekly interest rate $(0.999)$. Thus, one may wonder if our estimated model could actually be qualitatively very similar to a static model where consumers do not account for any future values. Specification (vi) tests this. We find that the static version of our baseline model generates very different preference parameter estimates. In particular, the model now predicts that one type buys used copies and sells immediately in the next week (notice that both buying and selling costs are lower for type-2 consumers) and that the other type buys new copies and never sell. As a result, it becomes very difficult to fit the volume sold by consumers (see its high standard deviations for measurement errors and shocks to selling). 
Table 10: Demand estimates: Alternative Specifications (i)-(iii)

(i)

\begin{tabular}{|c|c|c|c|c|c|c|}
\hline & \multicolumn{2}{|c|}{$\begin{array}{l}\text { heterogeneity only } \\
\text { in price sensitivity }\end{array}$} & \multicolumn{2}{|c|}{$\begin{array}{l}\text { add heterogeneity } \\
\text { in price sensitivity }\end{array}$} & \multicolumn{2}{|c|}{$\begin{array}{c}\text { add heterogeneity in } \\
\text { satiation-based depreciation }\end{array}$} \\
\hline & mean & s.d. & mean & s.d. & mean & s.d. \\
\hline \\
\hline discount factor $(\beta)$ & 0.906 & 0.001 & 0.906 & 0.001 & 0.902 & 0.001 \\
\hline \multicolumn{7}{|l|}{ price sensitivity } \\
\hline type-1 $\left(\alpha_{1}\right)$ & $5.01 \mathrm{E}-04$ & $1.21 \mathrm{E}-05$ & $2.57 \mathrm{E}-04$ & $7.63 \mathrm{E}-06$ & $2.95 \mathrm{E}-04$ & $6.92 \mathrm{E}-06$ \\
\hline type-2 $\left(\alpha_{2}\right)$ & $2.14 \mathrm{E}-04$ & $1.09 \mathrm{E}-05$ & $2.97 \mathrm{E}-04$ & $3.22 \mathrm{E}-06$ & same as type 1 & same as type 1 \\
\hline \multicolumn{7}{|l|}{ costs for buying a used copy } \\
\hline intercept for type-1 $\left(\lambda_{01}\right)$ & 0.918 & 0.008 & 0.107 & 0.067 & 0.173 & 0.052 \\
\hline $\begin{array}{r}\text { intercept for type-2 }\left(\lambda_{02}\right) \\
\text { inventory level }\end{array}$ & same as type 1 & same as type 1 & 1.32 & 0.055 & 1.75 & 0.094 \\
\hline coefficient $\left(\lambda_{1}\right)$ & 1.87 & 0.006 & 2.39 & 0.024 & 2.41 & 0.011 \\
\hline adjustment parameter $\left(\lambda_{2}\right)$ & $4.51 \mathrm{E}-04$ & 8.01E-06 & $5.02 \mathrm{E}-04$ & $7.75 \mathrm{E}-06$ & $4.98 \mathrm{E}-04$ & $7.59 \mathrm{E}-06$ \\
\hline \multicolumn{7}{|l|}{ costs for selling a used copy } \\
\hline type-1 $\left(\mu_{1}\right)$ & 4.55 & 0.010 & 9.70 & 0.063 & 9.70 & 0.088 \\
\hline type- $2\left(\mu_{2}\right)$ & same as type 1 & same as type 1 & 1.92 & 0.085 & 1.99 & 0.070 \\
\hline \multicolumn{7}{|c|}{ seasonal dummies } \\
\hline golden week (early May) $\left(\gamma_{1}\right)$ & 0.057 & 0.006 & 0.062 & 0.007 & 0.051 & 0.009 \\
\hline christmas (late Dec.) $\left(\gamma_{2}\right)$ & 0.298 & 0.007 & 0.273 & 0.006 & 0.252 & 0.016 \\
\hline \multicolumn{7}{|l|}{ outside options } \\
\hline intercept $\left(\pi_{0}\right)$ & 0.033 & 0.032 & 0.369 & 0.046 & 0.351 & 0.027 \\
\hline competitive effect $\left(\pi_{1}\right)$ & 0.228 & 0.009 & 0.176 & 0.010 & 0.181 & 0.009 \\
\hline \multicolumn{7}{|l|}{ depreciation rates } \\
\hline \multicolumn{7}{|l|}{ potential buyers } \\
\hline $1^{\text {st }}$-week intercept $\left(\phi_{1}\right)$ & -2.80 & 0.158 & -1.38 & 0.105 & -1.22 & 0.037 \\
\hline $2^{\text {na }}$-week intercept $\left(\phi_{2}\right)$ & -4.79 & 0.110 & -2.67 & 0.103 & -2.94 & 0.087 \\
\hline time since $3^{\text {ra }}$ week (logged) $\left(\phi_{3}\right)$ & -9.83 & 0.091 & -9.85 & 0.111 & -9.41 & 0.072 \\
\hline \multicolumn{7}{|l|}{ game owners } \\
\hline type-1 intercept $\left(\delta_{01}\right)$ & 1.54 & 0.011 & 1.74 & 0.016 & 1.75 & 0.006 \\
\hline type-2 intercept $\left(\delta_{02}\right)$ & same as type 1 & same as type 1 & same as type 1 & same as type 1 & 1.74 & 0.017 \\
\hline story-based $\left(\delta_{1}\right)$ & -0.550 & 0.008 & -0.621 & 0.010 & -0.636 & 0.007 \\
\hline multi-player $\left(\delta_{2}\right)$ & 0.164 & 0.020 & 0.302 & 0.011 & 0.328 & 0.027 \\
\hline critic rating $\left(\delta_{3}\right)$ & -0.328 & 0.012 & -0.003 & 0.005 & -0.006 & 0.010 \\
\hline user rating $\left(\delta_{4}\right)$ & 0.206 & 0.008 & -0.003 & 0.001 & -0.003 & 0.001 \\
\hline ownership duration (logged) $\left(\delta_{5}\right)$ & -0.806 & 0.020 & -0.629 & 0.017 & -0.613 & 0.009 \\
\hline proportion of type-1 consumers $\left(\psi_{1}\right)$ & 0.970 & 0.002 & 0.823 & 0.006 & 0.835 & 0.007 \\
\hline \multicolumn{7}{|l|}{ parameters for error terms } \\
\hline within-group correlation $(\eta)$ & 0.110 & 0.015 & 0.090 & 0.006 & 0.101 & 0.009 \\
\hline \multicolumn{7}{|l|}{ s.d.(measurement error) } \\
\hline sales new $\left(\varepsilon_{1}\right)$ & 250622.3 & 22537.2 & 116323.2 & 20027.5 & 118313.6 & 17527.0 \\
\hline sales used $\left(\varepsilon_{2}\right)$ & 3668.6 & 192.3 & 2961.5 & 130.6 & 3021.6 & 133.6 \\
\hline volume sold by consumers $\left(\varepsilon_{\mathrm{s}}\right)$ & 3306.4 & 329.0 & 2028.8 & 106.7 & 1979.3 & 92.6 \\
\hline \multicolumn{7}{|l|}{ s.d.(unobserved aggregate shocks) } \\
\hline sales new $\left(\xi_{1}\right)$ & 0.909 & 0.075 & 0.809 & 0.155 & 0.733 & 0.090 \\
\hline sales used $\left(\xi_{2}\right)$ & 0.281 & 0.034 & 0.219 & 0.023 & 0.223 & 0.023 \\
\hline volume sold by consumers $\left(\xi_{\mathrm{s}}\right)$ & 0.324 & 0.019 & 0.126 & 0.009 & 0.124 & 0.007 \\
\hline
\end{tabular}

Note: 20 game-specific intercepts $\left(\gamma^{\mathrm{g}}\right)$ are estimated but not reported here. "same as type 1 " indicates that the parameter is homogeneous. 
Table 11: Demand estimates: Alternative Specifications (iv)-(vi)

(iv)

correlation

between $\xi_{1}$ and $\xi_{2}$ (v)

(vi)

used-copy inventory

in utility function

for no purchase

\begin{tabular}{|c|c|c|c|c|c|c|}
\hline & mean & s.d. & mean & s.d. & mean & s.d. \\
\hline \multicolumn{7}{|l|}{ preference parameters } \\
\hline discount factor $(\beta)$ & 0.906 & 0.001 & 0.901 & 0.001 & 0 & \\
\hline price sensitivity $(\alpha)$ & $2.88 \mathrm{E}-04$ & 7.24E-06 & $2.78 \mathrm{E}-04$ & $7.43 \mathrm{E}-06$ & $9.93 \mathrm{E}-05$ & $1.37 \mathrm{E}-06$ \\
\hline \multicolumn{7}{|l|}{ costs for buying a used copy } \\
\hline intercept for type-1 $\left(\lambda_{01}\right)$ & 0.124 & 0.048 & 0.030 & 0.076 & 3.12 & 0.106 \\
\hline intercept for type-2 $\left(\lambda_{02}\right)$ & 1.47 & 0.048 & 1.28 & 0.066 & 0.358 & 0.028 \\
\hline inventory level & & & & & & \\
\hline coefficient $\left(\lambda_{1}\right)$ & 2.43 & 0.017 & 2.38 & 0.008 & 1.90 & 0.008 \\
\hline adjustment parameter $\left(\lambda_{2}\right)$ & 4.79E-04 & $1.04 \mathrm{E}-05$ & 4.87E-04 & $1.41 \mathrm{E}-05$ & $9.15 \mathrm{E}-04$ & $5.73 \mathrm{E}-06$ \\
\hline \multicolumn{7}{|l|}{ costs for selling a used copy } \\
\hline type-1 $\left(\mu_{1}\right)$ & 9.41 & 0.085 & 9.88 & 0.129 & 9.91 & 0.119 \\
\hline type-2 $\left(\mu_{2}\right)$ & 1.91 & 0.051 & 1.92 & 0.046 & 0.02 & 0.013 \\
\hline \multicolumn{7}{|l|}{$\underline{\text { seasonal dummies }}$} \\
\hline golden week (early May) $\left(\gamma_{1}\right)$ & 0.067 & 0.006 & 0.061 & 0.006 & 0.165 & 0.015 \\
\hline christmas (late Dec.) $\left(\gamma_{2}\right)$ & 0.269 & 0.018 & 0.251 & 0.008 & 0.090 & 0.004 \\
\hline \multicolumn{7}{|l|}{ outside options } \\
\hline intercept $\left(\pi_{0}\right)$ & 0.233 & 0.029 & 0.325 & 0.052 & 7.143 & 0.016 \\
\hline competitive effect $\left(\pi_{1}\right)$ & 0.197 & 0.007 & 0.193 & 0.013 & 0.778 & 0.007 \\
\hline inventory level & & & & & & \\
\hline coefficient $\left(\pi_{2}\right)$ & & & 0.006 & 0.001 & & \\
\hline adjustment parameter $\left(\pi_{3}\right)$ & & & $3.91 \mathrm{E}-04$ & $8.62 \mathrm{E}-05$ & & \\
\hline
\end{tabular}

\section{depreciation rates}

potential buyers

$1^{\text {st }}$-week intercept $\left(\phi_{1}\right)$

$2^{\text {na }}$-week intercept $\left(\phi_{2}\right)$

time since $3^{\text {ra }}$ week (logged) $\left(\phi_{3}\right)$

game owners

intercept $\left(\delta_{0}\right)$

story-based $\left(\delta_{1}\right)$

multi-player $\left(\delta_{2}\right)$

critic rating $\left(\delta_{3}\right)$

user rating $\left(\delta_{4}\right)$

ownership duration (logged) $\left(\delta_{5}\right)$
$-1.11$

$-2.93$

$-9.81$

1.74

$-0.662$

0.267

0.010

$-0.005$

$-0.603$

\section{parameters for error terms}

within-group correlation $(\eta)$

s.d.(measurement error) sales new $\left(\varepsilon_{1}\right)$

sales used $\left(\varepsilon_{2}\right)$

volume sold by consumers $\left(\varepsilon_{\mathrm{s}}\right)$

s.d.(unobserved aggregate shocks)

$$
\text { sales new }\left(\xi_{1}\right)
$$

sales used $\left(\xi_{2}\right)$

correlation $\left(\xi_{1}, \xi_{2}\right)$

volume sold by consumers $\left(\xi_{\mathrm{s}}\right)$

0.097

0.010

0.855

\subsection{1}

0.051

0.118

$-3.16$

$-9.93$

0.011

0.010

0.009

0.011

0.002

0.011

0.007

0.006

0.106

1.76

$-0.631$

0.301

$-0.005$

$-0.003$

$-0.594$

$103737.3 \quad 14065.0$

175.3

105120.4

3090.2

1963.5

0.877

0.223

0.112

0.520

0.348

0.024

0.005

0.136

0.008

0.041

$-1.37$

0.021

$-1.83$

0.026

0.084

0.009

0.010

1.72

0.014

0.007

0.353

0.013

0.011

0.556

0.008

0.002

$-0.525$

0.009

0.009

$-1.222$

0.006

0.009

0.006

1081.9

112.2

276.4

$9557.3 \quad 276.4$

Note: 20 game-specific intercepts $\left(\gamma^{\mathrm{g}}\right)$ are estimated but not reported here. 